\title{
High-frequency neural oscillations and visual processing deficits in schizophrenia
}

\author{
Heng-Ru May Tan ${ }^{1 *}$, Luiz Lana ${ }^{2,3,4}$ and Peter J. Uhlhaas ${ }^{1,3,4}$ \\ ' Institute of Neuroscience and Psychology, College of Science and Engineering and College of Medical, Veterinary and Life Sciences, University of Glasgow, \\ Glasgow, UK \\ 2 Brain Institute, Federal University of Rio Grande do Norte, Natal, Brazil \\ ${ }^{3}$ Department of Neurophysiology, Max-Planck Institute for Brain Research, Frankfurt, Germany \\ ${ }^{4}$ Ernst Strüngmann Institute (ESI) for Neuroscience in Cooperation with Max Planck Society, Frankfurt, Germany
}

\section{Edited by:}

Steven Silverstein, University of Medicine \& Dentistry of New Jersey, USA

Reviewed by:

Kevin M. Spencer, VA Boston Healthcare System/Harvard Medical School, USA

Shahab Ghorashi, Harvard Medical

School, USA

\section{*Correspondence:}

Heng-Ru May Tan, Centre for Cognitive Neuroimaging, Institute of Neuroscience and Psychology, College of Science and Engineering and College of Medical, Veterinary and Life Sciences, University of

Glasgow, 58 Hillhead Street,

Glasgow G12 8QB, UK

e-mail: Heng-RuMay.Tan@

glasgow.ac.uk
Visual information is fundamental to how we understand our environment, make predictions, and interact with others. Recent research has underscored the importance of visuo-perceptual dysfunctions for cognitive deficits and pathophysiological processes in schizophrenia. In the current paper, we review evidence for the relevance of high frequency (beta/gamma) oscillations towards visuo-perceptual dysfunctions in schizophrenia. In the first part of the paper, we examine the relationship between beta/gamma band oscillations and visual processing during normal brain functioning. We then summarize EEG/MEG-studies which demonstrate reduced amplitude and synchrony of high-frequency activity during visual stimulation in schizophrenia. In the final part of the paper, we identify neurobiological correlates as well as offer perspectives for future research to stimulate further inquiry into the role of high-frequency oscillations in visual processing impairments in the disorder.

Keywords: schizophrenia, high-frequency neural oscillations, visual perception, neurobiology, evoked and induced neural activity, neural synchrony

\section{DYSFUNCTIONS IN VISUAL PERCEPTION IN SCHIZOPHRENIA}

Disturbances in visual perception were for a long time considered relatively unimportant in the understanding of schizophrenia $(\mathrm{ScZ})$ compared to the more striking clinical presentation of hallucinations and delusions. Bleuer summarized this view as follows: "Sensory responses to external stimulus are quite normal. To be sure, the patients will complain that everything appears to be different. However, this strangeness is usually attributable to a deficit in customary associations and particularly to an alteration of emotional emphasis." (Bleuler, 1969; page 76). Similarly, Kraepelin (1919) concurred that "[P]erception of external impressions in dementia praecox is not usually lessened to any great extent as far as a superficial examination goes." (Kraepelin, 1971; page 5).

Following evidence from phenomenological research which indicated profound alterations in perceptual experience (see Uhlhaas and Mishara, 2007 for a review), an increasing number of studies began to investigate sensory processing experimentally (Place and Gilmore, 1980). Since then, a large body of evidence has accumulated that has highlighted impaired visual processing as a core deficit in schizophrenia (Klosterkötter et al., 2001; Javitt, 2009). Such dysfunctions involve the discrimination of orientation, motion, and object size (e.g., Butler and Javitt, 2005; Butler et al., 2007, 2008; Chen, 2011), which have been related to the magnocellular pathway because of reduced sensitivity to stimuli with low spatial frequency (Schechter et al., 2003; Butler and Javitt, 2005).

Moreover, ScZ-patients show reduced contextual influences in relationship to contrast (Yang et al., 2013), motion (Tadin et al., 2006), orientation (Yoon et al., 2010) as well as during contourintegration (Uhlhaas et al., 2006b), which could underlie impairments in perceptual organization (Uhlhaas and Silverstein, 2005). Additional visual processing deficits in ScZ have been revealed by masking paradigms (Green et al., 2011) which have highlighted longer intervals between the target and mask stimuli for accurate identification of targets (e.g., Green et al., 1994, 1999). Importantly, visual dysfunctions have been linked to impairments in higher cognitive functions (Javitt, 2009), such as working memory (Haenschel et al., 2009). Moreover, there is evidence to suggest that changes in visual perception are related to more complex features of the disorder, such as the development of delusions and changes in self-experiences (Uhlhaas and Mishara, 2007).

Data on abnormal visual functions in ScZ is consistent with evidence on anatomical abnormalities as revealed by postmortem studies (Selemon et al., 1995; Selemon and GoldmanRakic, 1999; Dorph-Petersen et al., 2007) as well as magnetic resonance (MR) and Diffusion Tensor Imaging (DTI) studies (Staal et al., 2000; Clasen et al., 2003; Arnone et al., 2009; White et al., 2011; Whitford et al., 2011b). These findings suggest that in addition to abnormalities in fronto-temporal regions, 
alterations in anatomical parameters extend to early visual areas. More recently, electro/magnetoencephalography (EEG/MEG) and functional magnetic resonance imaging (fMRI) have disclosed corresponding deficits in neural responses during visual stimulation (Spencer et al., 2003; Wynn et al., 2005; Uhlhaas and Singer, 2006; Uhlhaas et al., 2006a,b; Yeap et al., 2006). Specifically, studies assessing event-related potentials (ERPs) have demonstrated impairments during early and later visual processing stages in ScZ (Box 1).
Given that the visual system has been extensively explored through anatomy, electrophysiology and neuroimaging, detailed examination of visual dysfunctions in ScZ may allow insights into the underlying neurobiological correlates. In the following review, we will focus on the role of high-frequency neural oscillations because considerable evidence exists on the role of beta (13$25 \mathrm{~Hz})$ /gamma $(25-200 \mathrm{~Hz})$ band activity in visual processing as well as their potential involvement in the pathophysiology of ScZ. We will first examine the role of high-frequency neural activity

\section{Box 1 | Event-related potentials (ERPs), visual perception, and Schizophrenia}

ERP waveforms are commonly derived in EEG studies that investigate the neurophysiological mechanisms underlying sensory perception. ERP waveforms consist of a series of transient positive and negative voltage deflections that are time-locked to stimulus onset. These transient fluctuations in ERP waveform polarity are conventionally extracted as basic components and named by their polarity in conjunction with either their latency or ordinal position, relative to stimulus onset. In general, early components (e.g., those occurring before $\sim 200$ ms) are thought to reflect early sensory processing while higher cognitive processes are related to later components.

N80 - an initial negative deflection that peaks 70-90 ms post stimulus onset (Di Russo et al., 2007)—is considered the earliest visual ERP component and thought to be mainly driven by parvocellular (P) input but likely with small influence from the magnocellular (M) pathway in response to visual stimuli consisting of higher contrast levels (Foxe et al., 2008). In a recent investigation, using a range of visual stimuli that theoretically bias $\mathrm{M}$ or/and $\mathrm{P}$ pathways using systematic manipulation of stimulus luminance, chromatic contrasts and flicker, Núñez et al. (2013) demonstrated that the occipital N80 component in early-onset (but not adult-onset) ScZ was significantly lower in amplitude in response to stimuli that involve both $\mathrm{M}$ and $\mathrm{P}$ pathways. They also observed significantly prolonged onset of N80 latency in adult-onset ScZ. In contrast, the N80 amplitude in response to isolated P- and M-biased stimuli was comparable in both healthy controls and ScZ patients. The finding is suggestive of a deficit in M-priming on the P pathway in early-onset ScZ.

P1-a component with positive deflection $\sim 100 \mathrm{~ms}$ post visual stimulus onset—is known to involve the dorsal and ventral visual streams (Martinez et al., 1999; Di Russo et al., 2002). In response to visual stimuli (e.g., motion, spatial, low contrast) that bias the magnocellular pathway, the occipital P1 amplitude is commonly reported to be markedly decreased in patients with ScZ (e.g., Doniger et al., 2002; Schechter et al., 2005; Butler et al., 2007; Lalor et al., 2012; Núñez et al., 2013; however, see e.g., Johnson et al., 2005; Wynn et al., 2008, also mentioned below). Prominent P1 amplitude reduction was also observed in ScZ patients when they engaged in visual tasks involving illusory contour processing (Foxe et al., 2005) or fragmented object recognition (Doniger et al., 2002), and this reduction paralleled the weaker scalp activations over their lateral and posterior occipital areas.

N1-a negative component peak that manifests $\sim 150-200$ ms-is thought to predominantly reflect ventral stream processing (e.g., Doniger et al., 2002). Many studies that have assessed the N1 component, e.g., using illusory contour or fragmented contoured stimuli for object recognition, have reported comparable N1 amplitudes between ScZ patients and controls (e.g., Foxe et al., 2001; Doniger et al., 2002; Foxe et al., 2005), suggesting that parvocellular-mediated ventral stream processing is largely unaffected. However, studies that investigated face processing in ScZ patients have demonstrated pronounced reduction in their N170 amplitude in response to face vs. building stimuli (Herrmann et al., 2004b; Turetsky et al., 2007). Similar prominent reduction in N150 amplitude was observed in ScZ patients engaged in local vs. global visual perceptual tasks, and the amount of amplitude decrease in response to global stimuli correlated with corresponding performance accuracy and response times (Johnson et al., 2005). Further evidence of N1 amplitude reduction ( 200 post stimulus onset) is recently demonstrated in the fine-grain visual-masking discrimination task employed by (Plomp et al., 2013). Intriguingly, the extra time required by ScZ to reach normal discrimination performance levels did not alleviate the pronounced N1 amplitude reduction. Instead, as source analysis revealed, the discrimination difficulties are likely to be related to the significantly weaker parietal and lateral occipital activity in ScZ patients.

N250-a negative component that peaks $\sim 250 \mathrm{~ms}$ over fronto-central electrode sites-is considered sensitive to the emotional content of faces (Streit et al., 1999, 2001). Some studies have found reduced N250 amplitude in ScZ patients (e.g., Streit et al., 2001; Wynn et al., 2008) with normal N170 suggesting emotional information decoding deficits, while others have found the opposite (e.g., Johnson et al., 2005; Turetsky et al., 2007) suggesting that facial feature encoding is impaired rather than emotional information decoding.

$N_{C L}$ - a negative component that manifests $\sim 270-320 \mathrm{~ms}$ observed during visual tasks involving perceptual closure-is characterized by bilateral occipito-temporal scalp topography (Doniger et al., 2002) and is thought to reflect effortful extraction of object identity (Foxe et al., 2005). Significantly reduced $N_{C L}$ amplitude has been shown to be preceded by a normal N1 but prominently reduced P1 amplitude in ScZ patients (Doniger et al., 2002; Foxe et al., 2005). This observation has led to a view that the initial stages of visual ventral stream processes are unaffected in ScZ patients but the later stages of ventral stream processing involving object recognition are likely affected by indirect magnocellular-mediated dorsal stream inputs (e.g., Merigan and Maunsell, 1993; Nowak and Bullier, 1997; Schroeder et al., 1998) into the visual areas along the ventral stream (e.g., lateral occipital cortex).

P300 - a positive component that peaks $\sim 300-900$ ms post stimulus onset. Unlike earlier potentials, it is supposed to be an endogenous component which reflects stimulus context and levels of attention and arousal. The auditory P300 has consistently been shown to be impaired both in amplitude and latency (Bramon et al., 2004) while evidence for a dysfunctions during visual processing are less consistent (Ford, 1999); but see recent findings by Oribe et al. (2013) on prodromal and first-episode ScZ-patients. 
during normal visual perception emphasizing work from invasive and non-invasive electrophysiology followed by an overview of studies with EEG/MEG that have examined alterations in high-frequency oscillations in ScZ. In the final section, we will discuss potential mechanisms which could account for abnormal beta/gamma oscillations in $\mathrm{ScZ}$ as well as provide recommendation for future research.

\section{HIGH-FREQUENCY OSCILLATIONS AND VISUAL PROCESSING \\ INVASIVE ELECTROPHYSIOLOGY}

The involvement of gamma-band oscillations in sensory processing was first described by Adrian and colleagues in the 1940s (Adrian, 1950). Local field potential recordings from the olfactory bulb of anesthetized cats, rabbits, and hedgehogs showed pronounced oscillations in the $40-60 \mathrm{~Hz}$ frequency range. Subsequently, Freeman and colleagues (Bressler and Freeman, 1980; Freeman and Skarda, 1985) reported correlations between 35 and $85 \mathrm{~Hz}$ activity and olfactory perception, suggesting that gamma-band oscillatory modulations are involved in information coding in the olfactory system (Freeman, 1991).

Crucial evidence for a mechanistic role of gamma-band activity in visual perception and cortical computations was obtained by Singer and colleagues in the late 1980s (Singer, 1999). Specifically, Gray et al. (1989) showed that action potentials generated by cortical cells are phase-locked to the oscillatory gamma rhythm and consequently neurons aligned their discharges with high temporal precision. In its original formulation, the "Binding by Synchrony hypothesis" (BBS; Singer, 1999) proposed that ensembles of neurons that preferentially respond to features of the same object should fire synchronously, whereas these same neurons should not synchronize their firing to features belonging to other objects or to the background. Over the years, this hypothesis has gained substantial attention (for critical reviews see Gray, 1999; Shadlen and Movshon, 1999; Singer, 1999; Uhlhaas et al., 2009).

There is, however, conflicting evidence for the BBS in the primate primary visual area (V1) with some studies failing to find evidence for a relationship between binding of stimulus features and synchronous gamma-band activity (e.g., Lima et al., 2010). Given the large number of visual areas in the primate brain (Van Essen and Gallant, 1994), it is conceivable that binding through oscillatory mechanisms occurs in higher visual areas. Candidate brain regions would be structures that have been shown to express strong gamma oscillations in response to visual stimulation, such as the middle temporal cortex (MT) and V4 areas (e.g., Kreiter and Singer, 1996; Fries et al., 2001; but see also Thiele and Stoner, 2003; Palanca and DeAngelis, 2005). Nonetheless, it is important to note that the temporal and spatial scales for binding might be smaller than previously assumed and therefore even V1 remains as a viable candidate for binding (Fries et al., 2007; Havenith et al., 2011; Nikolić et al., 2013). These observations highlight the need to employ more sophisticated analysis techniques for the detection of transient signals that may be important for BBS.

In addition to stimulus parameters (see Box 2), the amplitude, and frequency of high-frequency oscillations in visual cortices can also be influenced by cognitive variables, such as attention. Initial evidence was provided by Fries and colleagues (Fries et al., 2001) who showed that $35-90 \mathrm{~Hz}$ activity in macaque visual area V4 strongly increased when behaviorally relevant stimuli were within the focus of attention. More recently, the same group demonstrated that spatial attention can also result in a shift to higher gamma-band frequencies in V1 (Bosman et al., 2012). Similarly, Lima et al. (2010) demonstrated using plaid stimuli that selective attention to one of the directional components of the plaid pattern affected gamma-band power in a manner that resembled the power (and frequency) modulation when the actual contrast of the stimulus was increased. Additionally, V1 gamma spectral power in macaques was shown to increase with temporal expectancy for behaviorally relevant events.

\section{EEG-MEG STUDIES}

Following the initial findings in both anaesthetized and awake animals on the potential relationship with visual processing (Singer and Gray, 1995), high-frequency oscillatory responses to visual stimuli have also been documented in EEG/MEG and electrocorticographic (ECoG) in humans (Sauvé, 1999; TallonBaudry and Bertrand, 1999; Lachaux et al., 2005; Tallon-Baudry, 2009; Martinovic and Busch, 2011). Broadly three different categories of high-frequency responses can be distinguished (Box 3).

Evoked high frequency oscillatory responses are typically observed $\sim 70-120 \mathrm{~ms}$ post stimulus with an occipital topography (e.g., Martinovic and Busch, 2011). Sources of evoked gamma activity during simple visual stimulus perception or object recognition have been localized to primary visual (Muthukumaraswamy et al., 2010), lateral occipital-temporal and inferior temporal cortical areas (Gruber et al., 2006). Amplitude and phase-locking of evoked high-frequency oscillations are modulated by stimulus properties. Corroborating invasive studies (Box 2), human neuroimaging research have also reported beta and gamma-band activity amplitude increases with contrast (Sannita et al., 1995; Schadow et al., 2007), stimulus duration, and size (Perry et al., 2013). In addition, spatial frequency modulates the power of high-frequency activity non-monotonically (Sannita et al., 1995; Tzelepi et al., 2000) and eccentricity decreases beta/gamma-band power (Busch et al., 2004; Fründ et al., 2007).

Due to their latency and topography, evoked high-frequency responses are likely to reflect feed forward driven responses (e.g., Butler and Javitt, 2005; Tobimatsu and Celesia, 2006; Martinovic and Busch, 2011). Early studies suggested that both amplitude and latency of evoked high-frequency activity were largely unaffected by experimental manipulations involving attention (e.g., Tallon et al., 1995; Tallon-Baudry et al., 1996, 1997). However, more recent findings (Herrmann et al., 1999; Frund et al., 2008) have challenged this view through demonstrating that top-down factors can impact on evoked gamma-band activity as well (e.g., Chaumon et al., 2009).

Following the link between binding of stimulus of elements into coherent representations and gamma-band oscillations in invasive recordings (Gray et al., 1989), several EEG 


\section{Box 2 | Stimulus parameters and high-frequency neural oscillations}

High-frequency oscillations are modulated by several important parameters, such as color, contrast, presentation eccentricity, orientation, and speed. The complexity of natural images makes it difficult to systematically explore the influence of any particular features on brain activity. Thus, simplified stimuli that can be parametrically changed over a feature space are typically employed. In particular, gratings are commonly used because they produce strong responses in the gamma frequency range. A brief overview of these parameters and their observed influence on high frequency oscillations are listed below.

\section{SIZE}

The effect of grating size on the activity recorded from the macaque primary visual area (V1) is such that bigger gratings generate stronger oscillations, lower peak frequency, and decreased firing rates (Gieselmann and Thiele, 2008; Jia et al., 2013a). Human MEG studies replicated the positive relationship between stimulus size and gamma frequency power, but failed to reproduce the effect of size modulating peak gamma frequency (Perry et al., 2013).

\section{POSITION}

The frequency of gamma oscillatory response is dependent on the apparent eccentricity of the stimulus. Centrally presented gratings tend to generate higher frequencies than stimuli presented peripherally (Lima et al., 2010).

\section{CONTRAST}

Gratings with higher contrast are associated with higher firing rates and increased gamma peak-frequency (Ray and Maunsell, 2010). The strength of gamma-band oscillations initially increases with contrast but if the contrast is too high there is a tendency for the oscillations to reduce in power (Ray and Maunsell, 2010; Jia et al., 2013b; Roberts et al., 2013).

\section{SPEED}

Gamma-band oscillations vary consistently with stimulus-velocity of bars (Gray et al., 1990) and gratings (Friedman-Hill et al., 2000; Lima et al., 2011). In humans, static gratings generate lower peak gamma frequencies than moving gratings (Swettenham et al., 2009; Muthukumaraswamy and Singh, 2013).

\section{SPATIAL FREQUENCY}

The spatial frequency of gratings is known to modulate gamma power (Adjamian et al., 2004) and firing rates (Lima et al., 2010) following an inverted $U$ relationship. Human neuroimaging data suggest that the peak frequency of gamma response is tuned to a narrow band of spatial frequency (2-4 cycles per degree; cpd), peaking at 3cpd (Adjamian et al., 2004); a finding not currently observed in monkey neurophysiology (Lima et al., 2010).

\section{ORIENTATION AND DIRECTION}

Animal neurophysiology has shown that gamma power and frequency are tuned to stimulus orientation and the direction of stimulus motion (Feng et al., 2010; Jia et al., 2013b). However, these effects have not yet been demonstrated in humans.

\section{NOISE LEVELS}

Progressively adding noise over a high contrast grating reduces the amplitude of gamma-band oscillations and their peak frequency without altering the average firing rates (Jia et al., 2011, 2013b).

\section{LUMINANCE PROFILE}

The luminance profile of a grating also influences gamma responses, with square waves generating more gamma power than sinusoidal gratings (Muthukumaraswamy and Singh, 2008).

\section{STIMULUS TYPE}

Gratings formed by concentric circles have been shown to produce higher gamma power compared to regular gratings formed by straight parallel elements (Muthukumaraswamy and Singh, 2013).

\section{STIMULUS COMPLEXITY}

Increases in stimulus complexity may lead to dramatic reductions in gamma-band power and also to changes in peak frequency (Lima et al., 2010).

\section{COLOR}

Pure color isoluminant gratings have been shown to produce undetectable gamma oscillations in human MEG recordings, that otherwise manifested strong gamma responses to luminance contrast gratings (Adjamian et al., 2008).

and MEG-studies have also examined the role of gamma-band oscillations during perceptual organization (Lutzenberger et al., 1995; Revonsuo et al., 1997; Keil et al., 1999; Spencer et al., 2003; Grützner et al., 2010), demonstrating increased amplitude and synchrony of gamma-band activity during the construction of coherent object representations. More recently, intracranial EEG data have complemented this evidence (Lachaux et al., 2005). 


\section{Box 3 | Measures of high-frequency oscillations}

Neural oscillations can be characterized by their frequency, amplitude, and phase. These characteristic features are derived through the time-frequency decomposition of electrophysiological signals by means of a Fourier, Wavelet or Multi-Taper analyses. These techniques estimate the strength (amplitude) and phase (time-variant angle) of the signal at a particular frequency range. A signal's phase consistency across trials, described as the phase-locking index, can be computed from its phase information (Lachaux et al., 1999, 2003). Apart from inter-trial oscillatory phase-locking, the same approach can also be used to assess the inter-areal synchrony of neural oscillations (Lachaux et al., 1999; Rodriguez et al., 1999; Gross et al., 2001; Varela et al., 2001; Siegel et al., 2008; Hipp et al., 2011). Importantly, this phaselocking index provides an estimation of neural synchrony irrespective of the amplitude of the oscillatory signal. This estimate of synchrony between signals is distinct from spectral coherence measures in which amplitude and phase information are intermixed (Gross et al., 2001).

Several different parameters of high-frequency activity can be distinguished which are frequently employed in the analysis of electrophysiological data (Tallon-Baudry et al., 1996; Roach and Mathalon, 2008).

(1) Evoked oscillations are phase- and time-locked to the stimulus onset, occurring $~ 70-120$ ms post stimulus onset. They are typically detected by averaging over a large number of single trials and then band-pass filtered at the frequency range of interest to assess the latency and peak amplitude of this averaged signal.

(2) Induced oscillatory responses manifest later than evoked responses with latencies $\sim 200-400$ ms and are not phase- locked to stimulus onset. Estimates of phase and amplitude are derived via time-frequency transformations (e.g., Morlet wavelets or Short Time Fourier Transforms) at single-trial level prior to averaging across trials.

(3) Repetitive presentation of a stimulus at a consistent frequency can lead to entrainment of neural activity at the stimulation frequency and is referred to as "steady-state" response (SSR, e.g., Herrmann, 2001). The peak of SSRs should typically correspond to the stimulation frequency, although responses to the harmonics of the stimulation frequency are also observed with reduced amplitude.

While induced oscillations are strongly enhanced by top-down factors (Vidal et al., 2006; Melloni et al., 2007), several studies have indicated that basic stimulus parameters, such as orientation (Edden et al., 2009), spatial frequency (Hadjipapas et al., 2007; Perry et al., 2013), luminance (Adjamian et al., 2008), and motion (Swettenham et al., 2009) also influence the occurrence of high-frequency activity. These findings, thus, challenge a simple dichotomy between evoked and induced activity. Moreover, recent findings demonstrated that sub-bands of low $(\sim 30-60 \mathrm{~Hz})$ and high $(\sim 70-120 \mathrm{~Hz})$ gamma-band oscillations are flexibly recruited by both feed-forward and feedback processes. For example, $30-60 \mathrm{~Hz}$ activity showed increases with initial unconscious associative learning of target-specific context in a search-task while $70-120 \mathrm{~Hz}$ oscillations occurred regardless of stimulus contexts (Chaumon et al., 2009). Likewise, amplitude of low gamma-band activity increases with conscious visual awareness in contrast to attention-related gamma band activity at higher frequencies (Wyart and Tallon-Baudry, 2008). The close association between the modulation of both low and high gamma band activity and cognitive processes further suggests that different gamma band frequencies could support the dynamic formation of distinct assemblies that underlie specific behavioral or cognitive function through "multiplexing" neural signal transmission (Vidal et al., 2006; Wyart and Tallon-Baudry, 2008).

\section{ALTERATIONS IN HIGH-FREOUENCY NEURAL OSCILLATIONS DURING VISUAL PROCESSING IN SCHIZOPHRENIA}

The wealth of research highlights that high-frequency neural oscillations are involved in perceptual processing during normal brain functioning (Herrmann et al., 2004a; Tallon-Baudry, 2009; Martinovic and Busch, 2011). It is therefore conceivable that disturbances in the amplitude and synchrony of beta/gammaband oscillations may have an important role in visual dysfunctions in ScZ. Indeed, a growing number of studies exploring this relationship have employed a range of visual tasks and assessed the integrity of the evoked and induced neural responses using different oscillatory parameters (see Table 1 for an overview and also Figure 1).

\section{SSVEPS}

Research investigating steady-state visually evoked potentials (SSVEPs) have observed reduced amplitude-modulation to repetitive stimulation at high but also at lower-frequencies in patients with schizophrenia relative to healthy controls. Krishnan et al. (2005) investigated SSVEPs to photic stimulation at frequencies from 4 to $40 \mathrm{~Hz}$ in EEG-recordings and reported decreased occipital amplitude modulation at 17,23 , and $30 \mathrm{~Hz}$ stimulation (Figure 1). In addition, higher "background noise," which was defined as averaged power of neural activity $1 \mathrm{~Hz}$ above and below the photic stimulation frequency, was observed at frequencies $4-20 \mathrm{~Hz}$ in ScZ-patients. The data from SSVEPs parallel findings from auditory entrainment experiments suggesting a basic impairment of cortical circuits to support high-frequency activity in ScZ. In contrast to visual SSVEPs, however, auditory entrainment impairments have been predominantly demonstrated at $40 \mathrm{~Hz}$ frequency stimulation (Kwon et al., 1999). Although more recent data have also demonstrated entrainments deficits at $80 \mathrm{~Hz}$ as well as at theta-frequency ranges (Hamm et al., 2011).

\section{EVOKED ACTIVITY}

Several studies have examined the integrity of evoked oscillations in ScZ using a variety of tasks. Backward masking paradigms are often used to assess early visual processing in ScZ. Given that basic features of any visual stimulus need to be integrated into a percept along the visual processing pathways, the effects of target percept masking could occur through the process of "integrating" the mask percept with the target percept, or through the process of "interrupting" the identification of target perception at a later 
Table 1 | Summary of EEG/MEG studies investigating high-frequency neural oscillations in patients with chronic schizophrenia and healthy controls during visual perceptual tasks.

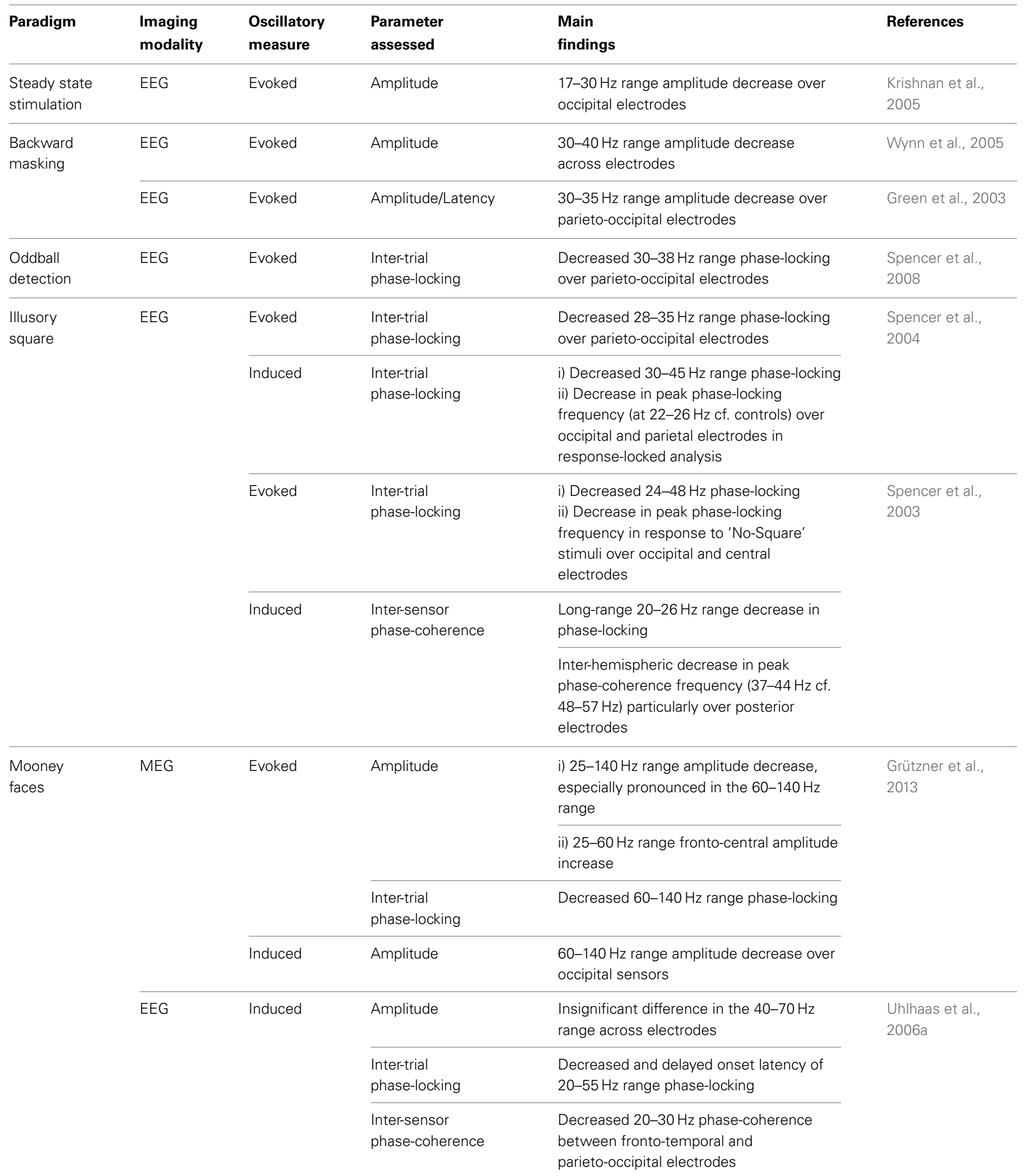

Main findings of these studies are reported in brief, highlighting the frequency range of significant effects observed in patients cf. healthy controls. 

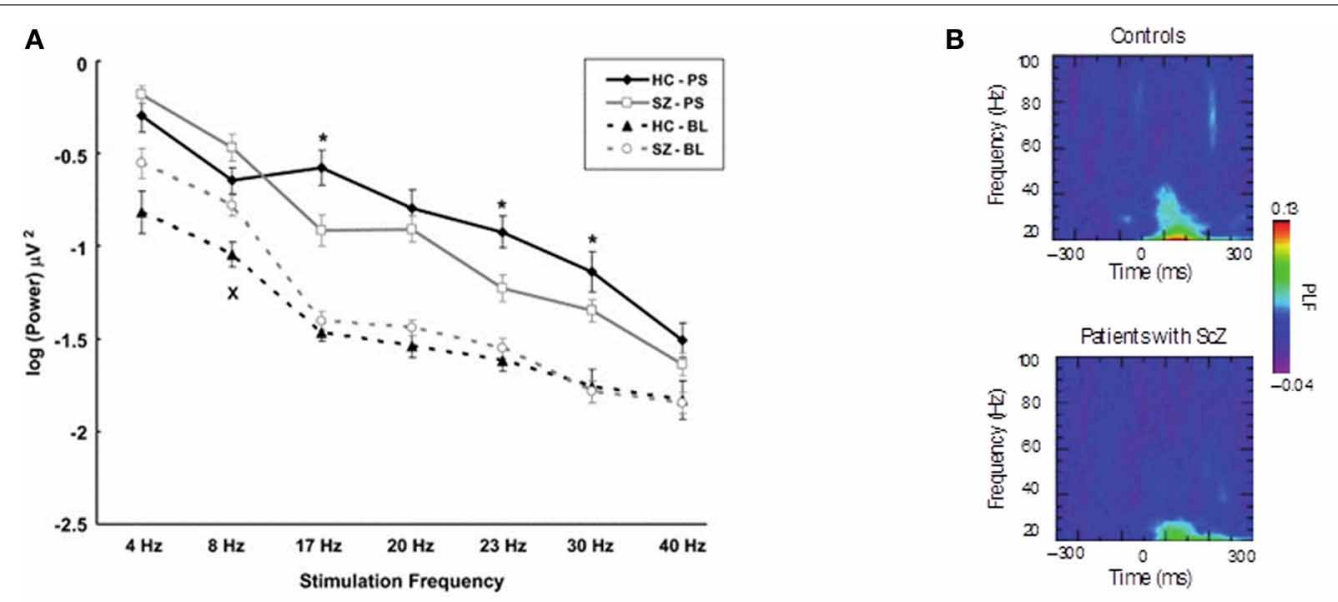

C
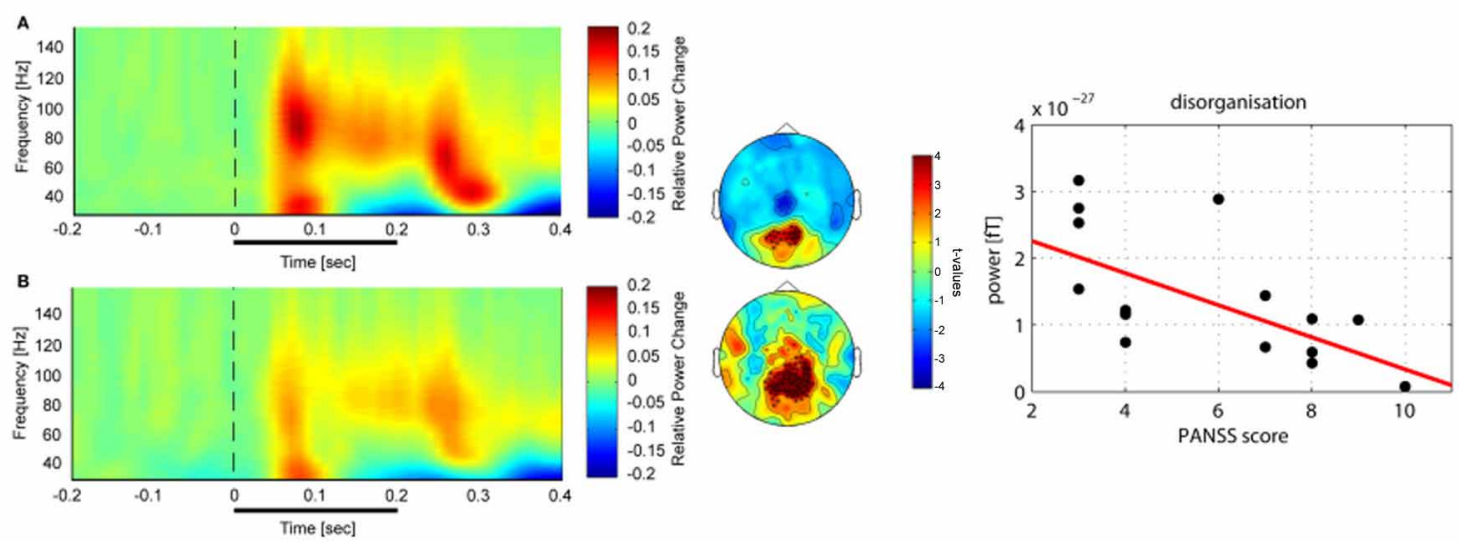

FIGURE 1 | (A) Visual steady-state potentials (SSP) in patients with schizophrenia and controls: Average signal power for the two groups during resting state and photic stimulation at different frequencies recorded at $\mathrm{Oz}$. (Legend: HC-PS, healthy control subjects during Photic Stimulation; SZ-PS, Schizophrenia subjects during Photic Stimulation; HC-BL, Healthy control subjects during Baseline; SZ-BL, Schizophrenia subjects during Baseline). Error bars indicate standard error. Significant differences between groups on ANOVAs are marked with "*" for the photic stimulation condition and " $x$ " for the resting condition. Adapted from Krishnan et al. (2005). (B) Sensory evoked oscillations during a visual oddball task in patients with schizophrenia. The colored scale indicates the phase locking factor (PLF) of oscillations in the $20-100 \mathrm{~Hz}$ frequency range in the occipital cortex (electrode 01 ) for healthy controls and patients with schizophrenia. Control participants show an increase in phase locking for gamma oscillations $\sim 100 \mathrm{~ms}$ after stimulus presentation. However, this is significantly smaller in patients with schizophrenia, indicating a dysfunction in early sensory processes. Adapted from Spencer et al. (2008). (C) High-Frequency Oscillations during Perceptual

Organization in ScZ. Left-Panel: Time-frequency representations and topographies of gamma-band spectral power of MEG-data in response to Mooney faces for controls (top) and chronic ScZ patients (bottom). The gamma-band signal is expressed as relative power change in the post-stimulus time window compared to baseline, averaged across all channels. The topographies (middle panels) display the results for a non-Parametric ANOVA indicating the main effects of group for both low (top) and high (bottom) gamma-band oscillations at the sensor level. Intensity of red indexes increased activity in controls while stronger blue intensities suggest increased gamma-band power in schizophrenia patients relative to controls. The topographies depict corrected $t$-values and the channels that form a statistically significant cluster are indicated $\left({ }^{*} p<0.001\right.$; $\left.{ }^{x} p<0.05\right)$. Right panel: Correlation between high gamma-band power and disorganization. The scatter-plot shows the relationship between high $(60-120 \mathrm{~Hz})$ gamma-band power in the $50-350 \mathrm{~ms}$ time window over positive channels and the disorganization component of the positive and negative syndrome scale. Adapted from Grützner et al. (2013).

stage of visual processing, or even via the process in which the target percept is "substituted" by that of the mask through a fastacting process (Green et al., 2011). ScZ patients and unaffected siblings require longer inter-stimuli-intervals (ISI) between the target-mask stimuli for accurate feature identification of briefly presented targets (Green et al., 1994, 1997; Kéri et al., 2001). Depending on the type of masking (e.g., integration, interruption, or substitution; Green et al., 2011) the prolonged ISI interval has been linked to deficits in the magnocellular $(\mathrm{M})$ and parvocellular (P) pathways (Schechter et al., 2003, 2005; Green et al., 2011).
The relationship between backward masking for location and object identification and gamma-band activity was examined in a series of studies by Green et al. (Green et al., 1999, 2003; Wynn et al., 2005). Systematic variation of inter-stimuli-intervals (ISIs) revealed that the response functions of ScZ-patients were best fitted with a continuous sine while in controls sensitivity to ISIs was consistent with a damped sinusoid (Green et al., 2003). Conversion of the wavelength parameter indicated that $30-35 \mathrm{~Hz}$ frequencies reflected best detection performance in controls. For ScZ-patients, the fitted sinusoids yielded a $32 \mathrm{~Hz}$ 
frequency conversion for the backward-masked location identification but a lower $15 \mathrm{~Hz}$ frequency for the backward-masked object identification.

To further link dysfunctions between backward masking and gamma-band activity, Green et al. (2003) also assessed EEG signals in response to backward masking of object identification in the $30-35 \mathrm{~Hz}$ frequency range. Peak latency in the $30-35 \mathrm{~Hz}$ spectral activity differed between groups with ScZ patients manifesting an earlier occipital-parietal peak around $100 \mathrm{~ms}$ while in controls gamma-bad activity was delayed ( $~ 200 \mathrm{~ms})$, suggesting intact sensory registration in ScZ-patients. A follow-up study by Wynn et al. (2005) reported, however, reduced 30-40 Hz spectral power in ScZ patients between 50 and $200 \mathrm{~ms}$ during backward masking. In addition, while controls expressed stronger spectral activity to incorrect (vs. correct) trials, the opposite was observed for ScZ patients. It is presently unclear whether backward masking deficits involve impaired evoked oscillations or whether later processing stages might be compromised.

Deficits in high-frequency oscillations are also observed in response to basic sensory stimuli. Spencer et al. (2008) examined evoked EEG responses to auditory and visual stimuli in chronic ScZ patients (Figure 1). Interestingly, ScZ-patients' spectral amplitude and measure of inter-trial phase-locking to auditory stimuli were comparable to healthy controls. In contrast, the 25-45 Hz visually-evoked gamma oscillatory response was absent in the phase-locking frequency maps of ScZ patients, whose $30-38 \mathrm{~Hz}$ phase-locking over occipital regions was significantly reduced.

Similarly, ScZ-patients are characterized by reduced gammaband responses to illusory square stimuli that presumably engage visual binding processes (Spencer et al., 2003, 2004). Spencer et al. (2003) showed that ScZ patients expressed a weaker P1 component which was accompanied by a reduced phase-locking of occipital evoked $(24-48 \mathrm{~Hz})$ activity to illusory square stimuli relative to controls. Moreover, ScZ patients' phase-locking over frontal-central EEG sensors were delayed in response to illusory squares, and occurred at lower frequencies. In a followup study, Spencer et al. (2004) examined response-time (RT) locked $(20-45 \mathrm{~Hz})$ evoked beta/gamma-band activity during the same paradigm and found reduced phase-locked activity in the $30-45 \mathrm{~Hz}$ frequency range in ScZ-patients which was accompanied by a shift to lower $(22-26 \mathrm{~Hz})$ activity relative to controls.

\section{INDUCED ACTIVITY}

Given that non-stimulus-locked (induced) oscillations, have been reported during perceptual organization processes during normal brain functioning (Rodriguez et al., 1999; Tallon-Baudry and Bertrand, 1999), it is likely that a focus on evoked activity only partially addresses the contribution of high-frequency activity toward visuo-perceptual dysfunctions in ScZ. To this end, two studies by Uhlhaas and colleagues (Uhlhaas et al., 2006a; Grützner et al., 2013) investigated induced beta/gamma spectral power during the viewing of Mooney faces, which involve the grouping of the fragmentary parts into coherent images based on the Gestalt principle of closure (Mooney and Ferguson, 1951). EEG-response to Mooney faces revealed largely intact gammaband activity in ScZ-patients relative to controls (Uhlhaas et al., 2006a). However, a subsequent study with MEG (Grützner et al., 2013) reported prominent reduction in evoked and induced $60-120 \mathrm{~Hz}$ spectral activity in ScZ-patients (effect size: $d=1.26$; Figure 1). Differences between the findings from EEG and MEGdata may be due to the fact MEG has improved sensitivity in detecting low-amplitude high-frequency oscillations than EEG (Muthukumaraswamy, 2013).

The findings of impaired induced gamma-band activity during perceptual organization are complemented by data showing reduced high-frequency activity during working memory and executive processes Haenschel et al. (2009) investigated gammaband activity in EEG-data during a visual working memory paradigm demonstrating significant reductions in gamma-band power at higher working memory load conditions in early-onset ScZ-patients. Similarly, Cho et al. (2006) reported a decrease in induced gamma-band power in chronic ScZ-patients during a cognitive control task which involved the inhibition of a prepotent response.

\section{LONG-RANGE SYNCHRONY}

In addition to the reduction in amplitude and consistency of evoked and induced spectral activity in ScZ patients, several studies have also assessed long-range neural synchrony through analyzing phase-synchronization between electrode pairs. This is of particular relevance because substantial evidence suggests that the functional networks underlying perception, attention, and executive processes rely on dynamic coordination through the inter-areal phase locking rhythmic activity (Lachaux et al., 1999; Varela et al., 2001). Spencer et al. (2003) observed a delayed onset of the $37-44 \mathrm{~Hz}$ phase synchrony as well as pronounced decreases in inter-hemispheric coherence during illusory-square perception over parietal electrodes in patients with ScZ. Moreover, Uhlhaas et al. (2006a) reported decreased phase-synchrony over fronto-temporal, and parieto-occipital sensors in the $200-300 \mathrm{~ms}$ period post stimulus onset, predominantly at beta $(20-30 \mathrm{~Hz})$ but also in the gamma-frequency range $(31-38 \mathrm{~Hz})$ during the perception of Mooney faces. The significant reductions in phasesynchrony observed in ScZ patients could indicate a global deficit in generating and sustaining synchrony both within local and also between distributed neural networks relevant for sensory processing.

\section{RELATIONSHIPS WITH CLINICAL VARIABLES}

Preliminary evidence suggests that alterations in high-frequency oscillations during visual processing in ScZ-patients may reflect psychopathological variables. Spencer et al. (Spencer et al., 2003 , 2004) reported that evoked phase-synchrony during illusory square perception was correlated with conceptual disorganization and visual hallucinations as well as a relationship between the lowered oscillation frequency and the expression of positive symptoms (delusions) and conceptual disorganization. Finally, Uhlhaas et al. (2006a) reported a positive relationship between 40 and $70 \mathrm{~Hz}$ phase synchrony and positive symptoms while a reduction of phasesynchronization correlated with elevated negative symptoms. Significant correlations have also been reported with spectral power. Reduced $60-120 \mathrm{~Hz}$ spectral power was found to correlate 
with elevated levels of disorganization by Grützner et al. (2013). However, an important issue is whether these observed alterations in high-frequency activity are independent of medication status. To date, the only published finding by Minzenberg et al. (2010) indicated that gamma-band activity during cognitive control was reduced in medication-naïve FE-ScZ-patients.

\section{PATHOPHYSIOLOGY OF VISUAL PROCESSING DEFICITS AND NEURAL OSCILLATIONS}

Visually elicited high-frequency oscillations might be ideally suited for translations research (Spencer, 2009; Uhlhaas and Singer, 2012). In the following section, we review the potential involvement of changes in excitatory-inhibition balance, anatomical parameters, and genetic factors that could provide plausible explanations for the breakdown of high-frequency neural oscillations and the associated visual dysfunction observed in ScZ.

\section{EXCITATORY-INHIBITION (E/I) BALANCE}

One important parameter for the generation of high-frequency oscillations in visual circuits but also in the cortex in general is the balance between excitation and inhibition (E/I-balance). Convergence of theoretical (Spencer, 2009; Kopell et al., 2010) and empirical studies (Whittington et al., 1995; Wang and Buzsáki, 1996; Traub et al., 2004) indicate that the generation of high-frequency oscillations crucially involve networks of inhibitory interneurons (Whittington et al., 1995; Bartos et al., 2007; Mann and Paulsen, 2007; Buzsáki and Wang, 2012) and glutamatergically mediated excitatory drive (Lukatch et al., 2005; Chamberlain et al., 2012). Specifically, basket cells which express calcium-binding parvalbumim (PV; Cardin et al., 2009; Sohal et al., 2009; Volman et al., 2011) are of particular relevance for the generation of high-frequency oscillations, specifically at gamma-band frequencies, because of their fastspiking properties (e.g., Buzsaki et al., 1983; Kawaguchi and Kubota, 1997).

More recently, optogenetic tools have enabled more precise links between changes in E/I-balance parameters and network oscillations to be established. For example, Sohal et al. (2009) showed that inhibition of PV interneurons led to an immediate suppression of $30-80 \mathrm{~Hz}$ oscillations while $10-30 \mathrm{~Hz}$ oscillations increased in power. In contrast, increasing PV-interneuron mediated feedback inhibition by boosting principal cell activity enhanced gamma-band power (Cardin et al., 2009).

Evidence suggests that E/I-balance parameters are disturbed in ScZ (Lewis et al., 2005, 2012). Specifically, the mRNA of GAD67 which synthesizes GABA is reduced in several cortical areas, including visual regions, in ScZ-patients (Akbarian et al., 1995; Mirnics et al., 2000; Hashimoto et al., 2003; Lewis et al., 2011, 2012). Moreover, this decrease is accompanied by reduced expression of the GABA membrane transporter 1 (GAT1; Volk et al., 2001; Lewis et al., 2005; Akbarian and Huang, 2006). GAT1 membrane transporters are expressed on chandelier neurons whose axon terminals synapse exclusively with the axonal initial segment of pyramidal neurons and thus uniquely regulate the excitatory pyramidal output (Lewis, 2000). Further evidence for a dysfunction in GABAergic transmission comes from magnetic resonance spectroscopy (1H-MRS) studies which have shown abnormal GABA-levels (Kegeles et al., 2012). Furthermore, MRS-measured reduction in GABA-levels was found to correlate with psychophysical impairment in orientation-specific surround suppression in ScZ patients (Yoon et al., 2010), suggesting a potential role in visual dysfunctions.

Additional parameters crucial for the generation of highfrequency oscillations include the AMPA- and NMDA-receptormediated activation of PV interneuron (Belforte et al., 2010; Carlén et al., 2012; Gonzalez-Burgos and Lewis, 2012). NMDAreceptor dysfunction has been implicated in the pathophysiology of ScZ through evidence from genetics (Carlén et al., 2012; Kirov et al., 2012) as well as from studies which have tested the impact of NMDA-receptor blockade on cortical processes. In healthy controls, Ketamine, an antagonist of the NMDAreceptor, elicits the full range of psychotic symptoms and impairments in cognitive processes, including visual perception (Hong et al., 2010). Furthermore, it has been shown in animal models that the blockade of NMDA-receptors induced aberrant high-frequency oscillations in extended cortical and subcortical networks (e.g., Hunt et al., 2011; Kittelberger et al., 2012; Phillips et al., 2012). For example, Anver et al. (2011) showed that NMDA-antagonists reduced the frequency of gammaband oscillations as well as induced phase coupling of the normally independent generating networks in cortical layers III and V. These findings suggest that E/I-balance is crucial in assuring coordinated occurrence of high-frequency activity during normal brain functioning in networks involved in visual processing. Consequently, abnormalities in these parameters could lead to changes in both amplitude and synchrony of beta/gamma-band oscillations and, in turn, lead to visual deficits.

\section{ANATOMICAL PARAMETERS}

In addition to the crucial contribution of GABAergic and glutamatergic neurotransmission towards high-frequency oscillations, anatomical parameters such as the layout of excitatory long-range connections have been implicated in long-range synchronization and the integrity of visual processing (Engel et al., 1991). Synchronization of oscillatory activity in the beta and gamma frequency range is dependent on cortico-cortical connections that reciprocally link cells situated in the same cortical area, in different areas, or even in different hemispheres (Engel et al., 1991). Interestingly, a recent study demonstrated that callosal connections contribute to the subjective experience of a visual motion stimulus that requires inter-hemispheric integration (Genc et al., 2011). As such, disruptions in the volume and organization of anatomical connectivity could impair longrange synchronization and impact on visual processes that require large-scale integration. However, a recent study that investigated inter-hemispheric transfer times with ERPs did not support this hypothesis in ScZ (Whitford et al., 2011a).

Further research is required to examine, in greater detail, the relationship between anatomical abnormalities and highfrequency oscillations. This is particularly relevant given the evidence from in vivo and post-mortem studies in patients with 
ScZ highlighting that both the volume and organization of white matter is abnormal, including both early and higher visual areas (Akbarian and Huang, 2006; Hashimoto et al., 2008). Additional evidence supporting the abnormal anatomy of visual regions was reported by Selemon et al. (1995) who observed increased neuronal density in area 17 (occipital cortex) as well as in area 9 (frontal cortex) in ScZ-patients. In contrast, Dorph-Petersen et al. (2007) found no difference in neuronal density in area 17 in ScZ and cortical thickness was in the normal range. However, the authors reported significantly reduced number of neurons as well as volumetric decreases in area 17 (Dorph-Petersen et al., 2007).

Abnormalities in gray matter could also potentially impact on the amplitude of neural oscillations as EEG/MEG signals are dependent on the ionic currents flowing in the dendrites of clusters of synchronously activated neurons during synaptic transmission that could be compromised by either reductions in the number of neurons and/or decreases in neuropil. Supporting a potential link between electrophysiological parameters and anatomical abnormalities in ScZ, Onitsuka et al. (2006) demonstrated an association between the degree of gray matter reduction and a decrease in the N170 ERP component.

\section{GENES}

With the genetic heritability of ScZ being estimated to be around 50-80\% (e.g., Sullivan et al., 2003; Harrison and Weinberger, 2004), one plausible hypothesis is that ScZ risk genes may influence the strength and frequency of neural oscillations in the disorder. Indeed, recent animal models which have examined the effects of risk genes on changes in high-frequency oscillations support this view. Carlson et al. (2011) investigated gammaband responses during auditory stimulation in mice with reduced dysbindin-1 expression which is a major ScZ risk gene (Straub et al., 2002; Ross et al., 2006; O’Tuathaigh et al., 2007). Deficits in early evoked gamma-band activity were found which were associated with a decrease in PV cell immune-reactivity. Similarly, Fisahn et al. (2009) demonstrated that polymorphisms in genes encoding Neuregulin-1 (NRG-1) and one of its receptors (ErbB4) selectively increase the power of in vitro gamma-band oscillations in hippocampal slices. Accordingly, these data suggest the possibility that ScZ-risk genes modify the E/I-balance parameters which in turn dysregulate the occurrence of high-frequency oscillations.

Recent evidence from genetic studies which have investigated the heritability of visually-induced gamma-band oscillations supports the utility of using high-frequency activity as an intermediate phenotype. van Pelt et al. (2012) recorded visually induced MEG-activity in monozygotic and dizygotic twin pairs (Figure 2). The peak-frequency of gamma-band oscillations were highly correlated in monozygotic but not in dizygotic twins, highlighting a strong genetic determination of gammaband oscillations. Additionally, reduced auditory evoked gammaband activity has been demonstrated in first-degree relatives of patients with schizophrenia as well as in unaffected, monozygotic twins with a high degree of heritability (Hall et al., 2011; Figure 2). Moreover, Hong et al. (2008) showed that abnormalities in theta- and alpha-band oscillations during sensory gating in ScZ-patients, their relatives, and healthy controls were characterized by heritability rates that exceeded those of traditional ERP measures.

\section{ISSUES FOR FUTURE RESEARCH}

The current review has shown a close relationship between visual processing and high-frequency oscillations during normal brain functioning as well as a potential link between aberrant beta/gamma-band activity and dysfunctional visual perception in ScZ. Given the known neurobiological parameters involved in the generation of high-frequency oscillations, we suggest that visually elicited high-frequency oscillations may constitute a useful window for gaining further insights into the pathophysiology of ScZ. To this end, we would like to raise several issues that we consider critical for future research.

The overall conclusion that can be drawn from the studies reviewed is that $\mathrm{ScZ}$ is associated with reductions in the amplitude, frequency, and/or synchronization of beta/gammaband oscillations during visual processing. Such deficits have been demonstrated during a wide range of task-conditions, such as in basic responses to visual entrainment (e.g., Krishnan et al., 2005), impaired stimulus-locking of oscillatory activity during perceptual binding (Spencer et al., 2003, 2004, 2008) and visual masking (Green et al., 1999, 2003; Wynn et al., 2005) as well as deficits in generating high-frequency oscillations (Grützner et al., 2013) and their large-scale integration during perceptual organization of complex stimuli (Spencer et al., 2003; Uhlhaas et al., 2006a,b). Abnormalities in visually elicited high-frequency oscillations are consistent with reduced beta/gamma-band activity during auditory (Kwon et al., 1999) and somatosensory perception (Arnfred et al., 2011). Together these findings suggest that cortical circuits in ScZ may be characterized by a comprehensive impairment in the mechanisms responsible for the generation and coordination of adequate high-frequency activity that is present in multiple regions and networks.

\section{HIGH-FREQUENCY OSCILLATIONS, THE VISUAL SYSTEM AND ScZ}

Psychophysical evidence has shown that ScZ-patients are characterized by several deficits in visual processing which include a deficit in stimuli involving the magnocellular pathway (Butler et al., 2008; Javitt, 2009), reduced contextual integration (Yoon et al., 2010; Dias et al., 2011; Yang et al., 2013) and dysfunctions in perceptual organization (Uhlhaas and Silverstein, 2005). Given that the amplitude and the frequency of beta/gammaband oscillations are closely related to stimulus properties during normal brain functioning (see Box 2), a combination of precise manipulation of stimulus parameters and electrophysiological approaches may yield novel insights into the relationship between visuo-perceptual dysfunctions and high-frequency oscillations in $\mathrm{ScZ}$.

A reported core deficit underlying visual dysfunction in ScZ is the gain control of visual neuronal responses in ScZ (Butler et al., 2008). Gain control refers to the ability of neurons to modulate their response amplitude and constitutes a general feature of cortical computations (Salinas and Thier, 2000). Impairments in gain control in ScZ are supported by reduced contrast sensitivity (Yang et al., 2013), impaired motion perception (Kim et al., 2006; 

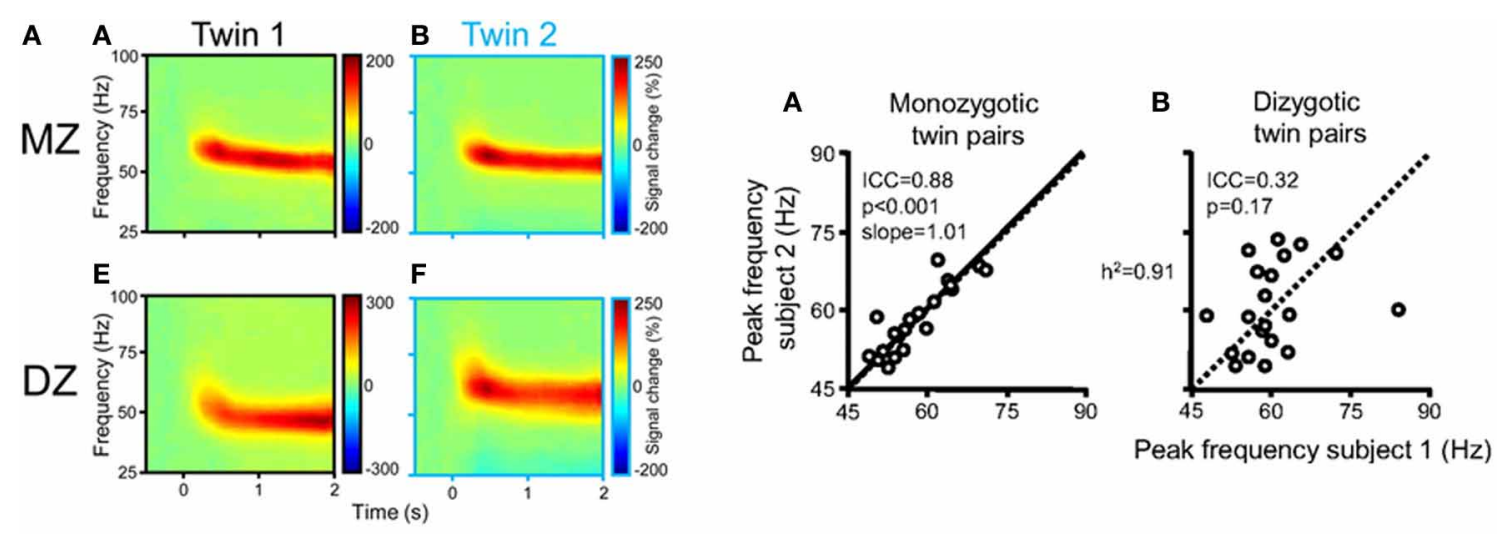

B

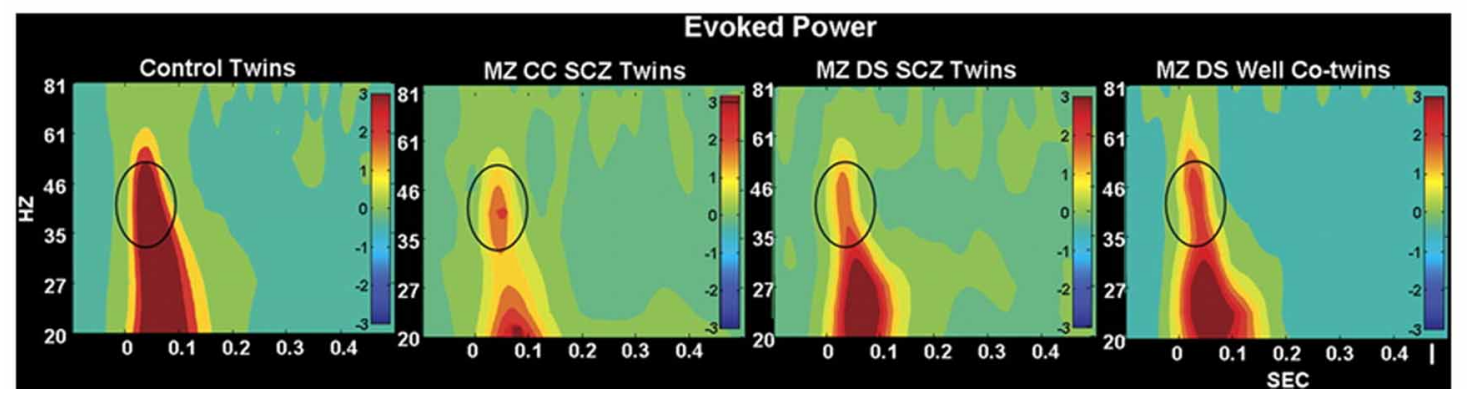

FIGURE 2 | (A) Left: visually induced gamma-band activity in MEG data in a monozygotic (MZ) and a dyzygotic (DZ) twin pair. Time-frequency representations (TFRs) of activity in the gamma-band range relative to prestimulus baseline levels in two twins of a MZ pair, averaged across 74 parieto-occipital MEG sensors. Time Os denotes stimulus onset. Right: correlation between gamma-peak frequencies in $M Z$ twins $[A]$ and $D Z$ twins [B]. Each data point represents the peak frequency of one twin vs. that of his or her co-twin (random axis assignment). Slope values are estimated by random permutations of $x$ and $y$ values. The data suggest a heritability of the gamma-band frequency of $91 \%$. Adapted from van Pelt et al. (2012).
(B) Evoked oscillatory activity in schizophrenia patients and their unaffected co-twins. EEG time-frequency analyses of evoked gamma-band power during an auditory oddball task for responses to the standard stimuli at electrode $\mathrm{Cz}$ in healthy twins, MZ twins concordant with schizophrenia, MZ twins discordant with schizophrenia, and unaffected co-twin members. Impaired evoked gamma-band power was significantly associated with schizophrenia and unaffected co-twins exhibited significantly reduced $30-60 \mathrm{~Hz}$ power as well-compared with controls, highlighting the genetic contribution toward impairments in high-frequency oscillations in the disorder. Adapted from Hall et al. (2011) by permission of Oxford University Press.
Chen, 2011) and contextual effects (Tadin et al., 2006; Yang et al., 2013; see also Butler et al., 2008 for a review). Moreover, neurophysiological studies have provided psychophysical evidence that these stimulus parameters, which are differentially processed in ScZ, modulate high-frequency activity. For example, increasing the contrast of visual stimuli enhances the frequency of the gamma-band rhythm in V1 (Ray and Maunsell, 2010) and V2 (Roberts et al., 2013). Similar findings have been observed for motion whereby static gratings are associated with lower peak frequencies than moving gratings (Gray et al., 1990; Swettenham et al., 2009; Muthukumaraswamy and Singh, 2013; see Box 2). Given these robust relationships, one option for future studies is to parametrically manipulate stimulus contrast and velocity and assess changes in high-frequency oscillations which could yield insights into the integrity of visual circuits in ScZ to support the occurrence and amplitude tuning of beta/gamma-band oscillations.

While such experiments are potentially important for probing dysfunctions in early visual regions, oscillatory dynamics are also crucially involved in mediating the influences of neuronal activity generated in anterior brain regions over the early stages of visual processing, such as during attention (Womelsdorf and Fries, 2007). Of relevance, evidence supporting the facilitatory effects of attention processes, particularly spatial attention, on visually induced high-frequency oscillations constitutes an additional example of gain control whereby neuronal responses to stimuli at attended locations are increased relatively to nonattended locations (Hillyard et al., 1998). This gain in neural response could be mediated through changes in the synchrony of inhibitory networks (Tiesinga et al., 2004a,b).

Previous psychophysical research in ScZ has implicated deficits in the utilization of top-down mediated cues (Silverstein et al., 1996) as well as dysfunctions in bottom-up driven processing in early visual pathways (Uhlhaas and Silverstein, 2005; Butler et al., 2007), suggesting that effects of attention on neural oscillations could be relevant in order to disentangle the contribution of feed-forward mediated vs. top-down processes toward visual deficits in ScZ. Recent studies from invasive electrophysiology (Fries et al., 2001; Ray et al., 2013) as well as from EEG/MEG (Wyart and Tallon-Baudry, 2008) have demonstrated that attention can lead to an increase in both the amplitude as well as the frequency shift of gamma-band activity (Kahlbrock 
et al., 2012; Koelewijn et al., 2013). These effects occur in early visual areas (Koelewijn et al., 2013) as well as at higher brain areas (Tallon-Baudry et al., 2005) and are accompanied by changes in the coherence of oscillations between early and higher visual regions (Siegel et al., 2008; Bosman et al., 2012). Therefore, detailed probing of attention effects on high-frequency oscillations could potentially offer insights into the differential (e.g., anatomical and frequency-specific) contribution of both bottom-up and top-down processes toward visual processing abnormalities in ScZ.

\section{VISUAL PERCEPTION, HIGH-FREQUENCY OSCILLATIONS IN ScZ AND TRANSLATIONAL RESEARCH}

One important issue concerns the possibility of distinct roles of beta and gamma-band oscillations during visual processing. Recent research have highlighted that beta-band oscillations mediate mainly top down activity and hence are critically involved in the prediction of upcoming sensory events while gammaband oscillations, at least in sensory cortices, are involved in feed-forward signalling (Buschman and Miller, 2007; Arnal and Giraud, 2012). This distinction is supported by the differential laminar expression of beta and gamma-band oscillations. In vitro and in vivo recordings show that gamma-band activity is prominently generated in superficial layers $2 / 3$ of the cortex (Buffalo et al., 2011), the main origin of feed- forward connections, and dependent upon fast, transient excitation of fast-spiking interneurons via metabotropic glutamate receptors (Whittington et al., 1995). In contrast, beta oscillations are mainly found in infragranular layers, from which feed-back projections originate preferentially. Interestingly, the generation of beta-band oscillations can be independent from excitatory or inhibitory synaptic transmission (Roopun et al., 2008). These observations provide potential hypotheses for future studies to investigate the differential contribution of beta/gamma-band oscillations during visual processing in ScZ. In particular, these investigations could be combined with the investigation of attention effects to address the potentially distinct roles of feed-forward vs. top-down mediated neuronal activity in perceptual dysfunctions in the disorder.

In addition to the modulation of beta/gamma-band power and synchrony, changes in the oscillatory peak-frequency may also be useful in establishing links between non-invasive EEG/MEGmeasures and E/I-balance parameters (see Spencer et al., 2004; Ferrarelli et al., 2012). It is conceivable that the frequency at which a network oscillates may more closely mirror biophysical parameters of the underlying network. For example, the deactivation kinetics of different GABAergic receptors strongly impact on the generation of fast vs. slow GABAergic currents which in turn are an important parameters for the frequency of oscillations (Wang and Buzsáki, 1996). Additionally, the peak-frequency of visually induced gamma-band activity in MEG-data has been shown to be under close genetic control (van Pelt et al., 2012), indicating that the frequency of gamma-band oscillations could be linked to genetically determined differences in channel-subunits.

Furthermore, mechanistic links between disturbed oscillations and visual perception in ScZ may also be established in combination with rhythmic stimulation through transcranial magnetic stimulation (TMS) and transcranial alternating current stimulation (tACS). Available evidence suggests that oscillatory brain processes can be entrained, enhanced or perturbed by means of external stimulation (Romei et al., 2011; Thut et al., 2011a,b; Antal and Paulus, 2013), which raises the possibility of targeting specific oscillations frequencies in conjunction with visuoperceptual processes in patients ScZ. The feasibility of using TMS, for example, to probe neural circuits in ScZ has been demonstrated in several recent studies (Ferrarelli et al., 2012; Frantseva et al., 2012).

Finally, future research should also consider the overlap in visually elicited high-frequency dysfunctions with related disorders, such as bipolar (BP) and autism spectrum disorders (ASDs). There is substantial evidence that ASDs are characterized by impairments in visual processing as well as deficits in high-frequency oscillations (Dakin and Frith, 2005; Sun et al., 2012). Similarly, there is evidence for impairments in bipolar disorder because auditory-steady state responses (O'Donnell et al., 2004) as well as long-range coherence (Özerdem et al., 2010) at gamma-band frequencies are significantly impaired.

Given the substantial overlap in genes, cognitive deficits and clinical symptoms between different diagnostic categories, it also conceivable that neural oscillations can be used to assign patients into novel categories based on neural oscillations. Fingerprints of neuronal dynamics, such as alterations in the frequency, temporal precision, phase locking, and topology of neuronal oscillations, during visual processing provide a rich coding-space for the definition of discrete entities or taxon (Meehl, 1992) within and also between diagnostic categories. As such, the close links between genes, neurobiology, and parameters (Figure 2) are perhaps wellsuited to identify pathways mediated by risk genes.

\section{BETA/GAMMA-BAND OSCILLATIONS AND LOW-FREOUENCY ACTIVITY}

While the current review focused on activity at beta/gamma-band frequencies, activity in lower frequencies ranges (e.g., delta, theta, alpha bands) may also be potential targets for understanding visual dysfunctions in ScZ. Existing evidence from EEG-studies suggests impaired amplitude and phase-locking during visual stimulation is not confined to beta/gamma-band frequencies (Haenschel et al., 2010; Hamm et al., 2012).

The alpha-band rhythm $(8-12 \mathrm{~Hz})$ is particularly relevant for the understanding of visual perception as the alpha cycle modulates perceptual detection rates (Valera et al., 1981; Dugué et al., 2011). Moreover, there is consistent evidence that oscillations in the alpha-band interact with the amplitude of gamma activity through cross-frequency coupling (Osipova et al., 2008), raising the possibility that impairments in high-frequency activity could also result from an impaired hierarchical organization of oscillations.

In addition to cross-frequency interactions, there is growing consensus that lower-frequency rhythms also play an important role in coordinating sensory predictions within and between modalities (see Schroeder and Lakatos, 2009 for a review). Recent work by Lakatos et al. (2013) demonstrated that impaired sensory discrimination of auditory stimuli in ScZ-patients was correlated with a deficit in effectively entraining inter-trial delta phaselocking to anticipate relevant sensory processing, and a failure 
to suppress task-irrelevant activity. These findings highlight the potential relevance of sensory predictions for auditory processing impairments in ScZ. It remains to be investigated whether predictive mechanisms in the visual domain are similarly affected in ScZ.

\section{METHODOLOGICAL IMPLICATIONS}

While it is possible that alterations in high-frequency oscillations during visual processing may reflect dysfunctions in specific variables involved in the generation of high-frequency activity, we cannot exclude the possibility that several non-specific factors, such as the impact of antipsychotic medication, chronic stress and the non-neuronal origin of certain EEG/MEG-signal components, contribute toward findings of impaired beta/gamma-band oscillations in ScZ patients. Accordingly, advances in analytic techniques and experimental designs are essential in order to allow clearer links between changes in high-frequencies oscillations and visuo-perceptual deficits in ScZ.

An approach to further identify such relationships is to employ single-trial analysis of EEG/MEG-data in combination with variation of stimulus parameters. At present, EEG/MEG-studies investigating high-frequency oscillations in ScZ have predominantly concentrated on differences in amplitude and peak-frequency values calculated across conditions or groups of participants. Given the substantial variability in behavioral and electrophysiological parameters both within and between groups, analysis of single-trial EEG/MEG-data analyses could potentially yield additional information as it allows a systematic mapping between brain activity and stimulus information as well as with indexes of behavioral variability (Pernet et al., 2011).

Furthermore, high-frequency oscillations during visual stimulation are accompanied by several important sources of artifacts which can resemble neuronally generated gamma band oscillations, and thus make the interpretation of EEG/MEG-signals difficult. Specifically, induced gamma-band activity coincides with the maximal frequency of micro-saccades which elicit a saccadic spike potential (SSP). Seminal work by (Yuval-Greenberg et al., 2008) highlighted that the SSP can mimic gamma oscillations in bandpass-filtered EEG signals if artifact-correction

\section{REFERENCES}

Adjamian, P., Hadjipapas, A., Barnes, G. R., Hillebrand, A., and Holliday, I. E. (2008). Induced Gamma activity in primary visual cortex is related to luminance and not color contrast: an MEG study. J. Vis. 8, 1-7. doi: 10.1167/ 8.7 .4

Adjamian, P., Holliday, I. E., Barnes, G. R., Hillebrand, A., Hadjipapas, A., and Singh, K. D. (2004). Induced visual illusions and gamma oscillations in human primary visual cortex. Eur. J. Neurosci. 20, 587-592. doi: 10.1111/j.1460-9568.2004.03495.x

Adrian, E. D. (1950). The electrical activity of the mammalian olfactory bulb. Electroencephalogr.

procedures are not adequately employed (Melloni et al., 2009). The presence of SSP-related gamma-band activity has also been recently demonstrated in MEG-recordings (Carl et al., 2012). Additionally, muscle artifacts can constitute another nonneuronal source of high-frequency activity that, if not carefully removed, can simulate power modulations in the gamma band range over visual regions (Whitham et al., 2007; see also Hipp and Siegel, 2013; Muthukumaraswamy, 2013 for recent reviews of these issues).

In addition to the contribution of eye-movement related artifacts toward high-frequency signals, a potentially important issue is also the relationship between neural oscillations, eyemovements, and visual dysfunctions. Abnormalities in the several eye-movement parameters such as smooth pursuit, fixation stability, scan-path, and fixation dispersal during free viewing are one of the more robust domains of impairments in ScZ-patients (e.g., Benson et al., 2012). Moreover, recent findings suggest that patterns of saccades strongly modulate the occurrence of high-frequency oscillations in V1 (Bosman et al., 2009) and that different oscillatory frequencies are involved in the organization of eye-movement patterns (Ito et al., 2011). Indeed, disentangling the relationship between high-frequency oscillations, eye-movements, and visual processing dysfunctions will be an important albeit challenging area of research.

\section{SUMMARY}

The findings reviewed suggest a potential link between the occurrence of beta/gamma oscillations and the pronounced deficits in visual perception in ScZ. Evidence supporting such a relationship comes from EEG/MEG studies indicating reductions in synchrony and amplitude of beta/gamma-band oscillations during basic and complex visual stimuli as well through anatomical findings that highlight impaired structure and composition of visual circuits in the disorder. Importantly, given the known mechanisms involved in the genesis of high-frequency oscillations, the evidence and clinical importance of visual dysfunctions in ScZ, as well as the opportunity to measure high-frequency oscillations non-invasively, visually elicited high-frequency oscillations in ScZ are potentially suited for translational research.

Antal, A., and Paulus, W. (2013). Transcranial alternating current stimulation (tACS). Front. Hum. Neurosci. 7:317. doi: 10.3389/fnhum.2013.00317

Anver, H., Ward, P. D., Magony, A., and Vreugdenhil, M. (2011). NMDA receptor hypofunction phase couples independent $\gamma$ oscillations in the rat visual cortex. Neuropsychopharmacol. 36, 519-528. doi: 10.1038/npp. 2010.183

Arnal, L. H., and Giraud, A. (2012). Cortical oscillations and sensory predictions. Trends Cogn. Sci. (Regul. Ed.) 16, 390-398. doi: 10.1016/j.tics.2012.05.003

Arnfred, S. M. H., Mørup, M., Thalbitzer, J., Jansson, L., and
Parnas, J. (2011). Attenuation of beta and gamma oscillations in schizophrenia spectrum patients following hand posture perturbation. Psychiatry Res. 185, 215-224. doi: 10.1016/j.psychres.2009.10.005

Arnone, D., Cavanagh, J., Gerber, D., Lawrie, S. M., Ebmeier, K. P., and McIntosh, A. M. (2009). Magnetic resonance imaging studies in bipolar disorder and schizophrenia: meta-analysis. $\mathrm{Br}$. J. Psychiatry 195, 194-201. doi: 10.1192/bjp.bp.108.059717

Bartos, M., Vida, I., and Jonas, P. (2007). Synaptic mechanisms of synchronized gamma oscillations in inhibitory interneuron networks. Nat. Rev. Neurosci. 8, 45-56. doi: 10.1038/nrn2044 
Belforte, J. E., Zsiros, V., Sklar, E. R., Jiang, Z., Yu, G., Li, Y., et al. (2010). Postnatal NMDA receptor ablation in corticolimbic interneurons confers schizophrenia-like phenotypes. Nat. Neurosci. 13, 76-83. doi: 10.1038/nn.2447

Benson, P. J., Beedie, S. A., Shephard, E., Giegling, I., Rujescu, D., and St. Clair, D. (2012). Simple viewing tests can detect eye movement abnormalities that distinguish schizophrenia cases from controls with exceptional accuracy. Biol. Psychiatry 72, 716-724. doi: 10.1016/j.biopsych. 2012.04.019

Bleuler, E. (1969). Dementia Praecox; or, the Group of Schizophrenias. Transl. Joseph Zinkin; foreword by Nolan C. D. Lewis. (New York, NY: International Universities Press; Originally published in 1911)

Bosman, C., Schoffelen, J., Brunet, N., Oostenveld, R., Bastos, A., Womelsdorf, T., et al. (2012). Attentional stimulus selection through selective synchronization between monkey visual areas. Neuron 75, 875-888. doi: 10.1016/j.neuron.2012.06.037

Bosman, C. A., Womelsdorf, T., Desimone, R., and Fries, P. (2009). A microsaccadic rhythm modulates gamma-band synchronization and behavior. $J$. Neurosci. 29, 9471-9480. doi: 10.1523/JNEUROSCI.1193-09.2009

Bramon, E., Rabe-Hesketh, S., Sham, P., Murray, R. M., and Frangou, S. (2004). Meta-analysis of the P300 and P50 waveforms in schizophrenia. Schizophr. Res. 70, 315-329. doi: 10.1016/j.schres.2004.01.004

Bressler, S. L., and Freeman, W. J. (1980). Frequency analysis of olfactory system EEG in cat, rabbit, and rat. Electroencephalogr. Clin. Neurophysiol. 50, 19-24. doi: 10.1016/0013-4694(80)90319-3

Buffalo, E. A., Fries, P., Landman, R., Buschman, T. J., and Desimone, R. (2011). Laminar differences in gamma and alpha coherence in the ventral stream. Proc. Natl. Acad. Sci. U.S.A. 108, 11262-11267. doi: 10.1073/pnas.1011284108

Busch, N. A., Debener, S., Kranczioch, C., Engel, A. K., and Herrmann, C. S. (2004). Size matters: effects of stimulus size, duration and eccentricity on the visual gamma-band response. Clin. Neurophysiol. 115, 1810-1820. doi: 10.1016/j.clinph.2004.03.015

Buschman, T. J., and Miller, E. K. (2007). Top-down versus bottom-up control of attention in the prefrontal and posterior parietal cortices. Science 315, 1860-1862. doi: 10.1126/science. 1138071

Butler, P. D., and Javitt, D. C. (2005). Early-stage visual processing deficits in schizophrenia. Curr. Opin. Psychiatry 18, 151-157. doi: 10.1097/00001504-20050300000008

Butler, P. D., Martinez, A., Foxe, J. J., Kim, D., Zemon, V., Silipo, G., et al. (2007). Subcortical visual dysfunction in schizophrenia drives secondary cortical impairments. Brain 130, 417-430. doi: 10.1093/brain/awl233

Butler, P. D., Silverstein, S. M., and Dakin, S. C. (2008). Visual perception and its impairment in schizophrenia. Biol. Psychiatry 64, 40-47. doi: 10.1016/j.biopsych.2008.03.023

Buzsaki, G., Leung, L. W., and Vanderwolf, C. H. (1983) Cellular bases of hippocampal EEG in the behaving rat. Brain Res. 287, 139-171. doi: 10.1016/0165-0173(83)90037-1

Buzsáki, G., and Wang, X. (2012). Mechanisms of gamma oscillations. Annu. Rev. Neurosci. 35, 203-225. doi: 10.1146/annurevneuro-062111-150444

Cardin, J. A., Carlen, M., Meletis, K., Knoblich, U., Zhang, F., Deisseroth, K., et al. (2009). Driving fastspiking cells induces gamma rhythm and controls sensory responses. Nature 459, 663-667. doi: 10.1038/ nature 08002

Carl, C., Açık, A., König, P., Engel, A. K., and Hipp, J. F. (2012). The saccadic spike artifact in MEG. Neuroimage 59, 1657-1667.

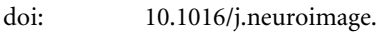
2011.09.020

Carlén, M., Meletis, K., Siegle, J. H. Cardin, J. A., Futai, K., et al. (2012). A critical role for NMDA receptors in parvalbumin interneurons for gamma rhythm induction and behavior. Mol. Psychiatry 17, 537-548. doi: 10.1038/ mp.2011.31

Carlson, G. C., Talbot, K., Halene, T. B., Gandal, M. J., Kazi, H. A., Schlosser, L., et al. (2011). Dysbindin-1 mutant mice implicate reduced fast-phasic inhibition as a final common disease mechanism in schizophrenia. Proc. Natl. Acad. Sci. U.S.A. 108, 962-970. doi: 10.1073/ pnas. 1109625108

Chamberlain, S. E. L., Jane, D. E., and Jones, R. S. G. (2012). Pre- and post-synaptic functions of kainate receptors at glutamate and GABA synapses in the rat entorhinal cortex. Hippocampus 22, 555-576. doi: 10.1002/hipo.20921
Chaumon, M., Schwartz, D., and Tallon-Baudry, C. (2009). Unconscious learning versus visual perception: dissociable roles for gamma oscillations revealed in MEG. J. Cogn. Neurosci. 21, 2287-2299. doi: 10.1162/jocn.2008.21155

Chen, Y. (2011). Abnormal visual motion processing in schizophrenia: a review of research progress. Schizophr. Bull. 37, 709-715. doi: 10.1093/schbul/sbr020

Cho, R. Y., Konecky, R. O., and Carter, C. S. (2006). Impairments in frontal cortical $\gamma$ synchrony and cognitive control in schizophrenia. Proc. Natl. Acad. Sci. U.S.A. 103, 19878-19883. doi: 10.1073/pnas.0609440103

Clasen, L. S., Giedd, J. N., Gochman, P. A., Gogtay, N., Greenstein, D., Lenane, M., et al. (2003). Structural brain MRI abnormalities in healthy siblings of patients with childhood-onset schizophrenia. Am. J. Psychiatry 160, 569-571. doi: 10.1176/appi.ajp.160.3.569

Dakin, S., and Frith, U. (2005) Vagaries of visual perception in autism. Neuron 48, 497-507. doi: 10.1016/j.neuron.2005.10.018

Dias, E. C., Butler, P. D., Hoptman, M. J., and Javitt, D. C. (2011). Early sensory contributions to contextual encoding deficits in schizophrenia. Arch. Gen. Psychiatry 68, 654-664. doi: 10.1001/archgenpsychiatry.2011.17

Di Russo, F., Martínez, A., Sereno, M. I., Pitzalis, S., and Hillyard, S. A. (2002). Cortical sources of the early components of the visual evoked potential. Hum. Brain Mapp. 15, 95-111. doi: 10.1002/hbm.10010

Di Russo, F., Pitzalis, S., Aprile, T., Spitoni, G., Patria, F., Stella, A., et al. (2007). Spatiotemporal analysis of the cortical sources of the steady-state visual evoked potential. Hum. Brain Mapp. 28, 323-334. doi: 10.1002/hbm.20276

Doniger, G. M., Foxe, J. J., Murray, M. M., Higgins, B. A., and Javitt, D. C. (2002). Impaired visual object recognition and dor$\mathrm{sal} /$ ventral stream interaction in schizophrenia. Arch. Gen. Psychiatry 59, 1011-1020. doi: 10.1001/archpsyc.59.11.1011

Dorph-Petersen, K., Pierri, J. N., Wu, Q., Sampson, A. R., and Lewis, D. A. (2007). Primary visual cortex volume and total neuron number are reduced in schizophrenia. J. Comp. Neurol. 501, 290-301. doi: 10.1002/cne.21243

Dugué, L., Marque, P., and VanRullen, R. (2011). The phase of ongoing oscillations mediates the causal relation between brain excitation and visual perception. J. Neurosci. 31, 11889-11893. doi: 10.1523/JNEUROSCI.1161-11.2011

Edden, R. A. E., Muthukumaraswamy, S. D., Freeman, T. C. A., and Singh, K. D. (2009). Orientation discrimination performance is predicted by gaba concentration and gamma oscillation frequency in human primary visual cortex. J. Neurosci. 29, 15721-15726. doi: 10.1523/JNEUROSCI.442609.2009

Engel, A. K., Konig, P., Kreiter, A. K., and Singer, W. (1991). Interhemispheric synchronization of oscillatory neuronal responses in cat visual cortex. Science 252, 1177-1179. doi: 10.1126/science.252.5009.1177

Feng, W., Havenith, M. N., Wang, P., Singer, W., and Nikolic, D. (2010). Frequencies of gamma/beta oscillations are stably tuned to stimulus properties. Neuroreport 21, 680-684. doi: 10.1097/WNR.0b013e32833ae9d1

Ferrarelli, F., Sarasso, S., Guller, Y., Riedner, B. A., Peterson, M. J., Bellesi, M., et al. (2012). Reduced natural oscillatory frequency of frontal thalamocortical circuits in schizophrenia. Arch. Gen. Psychiatry 69, 766-774. doi: 10.1001/archgenpsychiatry.2012.147

Fisahn, A., Neddens, J., Yan, L., and Buonanno, A. (2009). Neuregulin-1 modulates hippocampal gamma oscillations: implications for schizophrenia. Cereb. Cortex 19, 612-618. doi: 10.1093/cercor/bhn 107

Ford, J. M. (1999). Schizophrenia: the broken P300 and beyond. Psychophysiology 36, 667-682. doi: 10.1111/1469-8986.3660667

Foxe, J. J., Doniger, G. M., and Javitt, D. C. (2001). Early visual processing deficits in schizophrenia: impaired P1 generation revealed by high-density electrical mapping. Neuroreport 12, 3815-3820. doi: $\quad 10.1097 / 00001756-2001120$ 40-00043

Foxe, J. J., Murray, M. M., and Javitt, D. C. (2005). Filling-in in schizophrenia: a high-density electrical mapping and source-analysis investigation of illusory contour processing. Cereb. Cortex 15, 1914-1927. doi: 10.1093/cercor/bhi069

Foxe, J. J., Strugstad, E., Sehatpour, P., Molholm, S., Pasieka, W., Schroeder, C. E., et al. (2008). Parvocellular and Magnocellular contributions to the initial generators of the visual evoked potential: high-density electrical 
mapping of the ' $\mathrm{Cl}$ ' component. Brain Topogr. 21, 11-21. doi: 10.1007/s10548-008-0063-4

Frantseva, M., Cui, J., Farzan, F., Chinta, L. V., Perez Velazquez, J. L., and Daskalakis, Z. J. (2012). Disrupted cortical conductivity in schizophrenia: TMS-EEG study. Cereb. Cortex. doi: 10.1093/cercor/bhs304. [Epub ahead of print].

Freeman, W. J. (1991). The physiology of perception. Sci. Am. 264, 78-85. doi: 10.1038/scientificamerican0291-78

Freeman, W. J., and Skarda, C. A. (1985). Spatial EEG patterns, non-linear dynamics and perception: the neo-sherringtonian view. Brain Res. Rev. 10, 147-175. doi: 10.1016/0165-0173(85)90022-0

Friedman-Hill, S., Maldonado, P. E., and Gray, C. M. (2000). Dynamics of striate cortical activity in the alert macaque: I. Incidence and stimulus-dependence of gamma-band neuronal oscillations. Cereb. Cortex 10, 1105-1116. doi: 10.1093/cercor/10.11.1105

Fries, P., Nikolic, D., and Singer, W. (2007). The gamma cycle. Trends Neurosci. 30, 309-316. doi: 10.1016/j.tins.2007.05.005

Fries, P., Reynolds, J. H., Rorie, A. E., and Desimone, R. (2001). Modulation of oscillatory neuronal synchronization by selective visual attention. Science 291, 1560-1563. doi: 10.1126/science. 1055465

Fründ, I., Schadow, J., Busch, N. A., Körner, U., and Herrmann, C. S. (2007). Evoked $\gamma$ oscillations in human scalp EEG are test-retest reliable. Clin. Neurophysiol. 118, 221-227. doi: 10.1016/j.clinph.2006.09.013

Frund, I., Schadow, J., Busch, N. A., Naue, N., Korner, U., and Herrmann, C. S. (2008). Anticipation of natural stimuli modulates EEG dynamics: physiology and simulation. Cogn. Neurodyn. 2, 89-100. doi: 10.1007/s11571-008-9043-3

Genc, E., Bergmann, J., Tong, F., Blake, R., Singer, W., and Kohler, A. (2011). Callosal connections of primary visual cortex predict the spatial spreading of binocular rivalry across the visual hemifields. Front. Hum. Neurosci. 5:161. doi: 10.3389/fnhum.2011.00161

Gieselmann, M. A., and Thiele, A. (2008). Comparison of spatial integration and surround suppression characteristics in spiking activity and the local field potential in macaque V1. Eur. J. Neurosci. 28, 447-459. doi: $\quad 10.1111 /$ j.1460-9568.2008. 06358.x

Gonzalez-Burgos, G., and Lewis, D. A. (2012). NMDa receptor hypofunction, parvalbumin-positive neurons, and cortical gamma oscillations in schizophrenia. Schizophr. Bull. 38, 950-957. doi: 10.1093/schbul/sbs010

Gray, C. M. (1999). The temporal correlation hypothesis of visual feature integration: still alive and well. Neuron 24, 31-47. doi: 10.1016/S0896-6273(00)80820-X

Gray, C. M., Engel, A. K., König, P., and Singer, W. (1990). Stimulusdependent neuronal oscillations in cat visual cortex: receptive field properties and feature dependence. Eur. J. Neurosci. 2, 607-619. doi: 10.1111/j.14609568.1990.tb00450.x

Gray, C. M., Konig, P., Engel, A. K., and Singer, W. (1989). Oscillatory responses in cat visual cortex exhibit inter-columnar synchronization which reflects global stimulus properties. Nature 338, 334-337. doi: $10.1038 / 338334 \mathrm{a} 0$

Green, M. F., Lee, J., Wynn, J. K., and Mathis, K. I. (2011). Visual masking in schizophrenia: overview and theoretical implications. Schizophr. Bull. 37, 700-708. doi: 10.1093/schbul/sbr051

Green, M. F., Mintz, J., Salveson, D., Nuechterlein, K. H., Breitmeyer, B., Light, G. A., et al. (2003). Visual masking as a probe for abnormal gamma range activity in schizophrenia. Biol. Psychiatry 53, 1113-1119. doi: 10.1016/S00063223(02)01813-9

Green, M. F., Nuechterlein, K. H., and Breitmeyer, B. (1997). Backward masking performance in unaffected siblings of schizophrenic patients: evidence for a vulnerability indicator. Arch. Gen. Psychiatry 54, 465-472. doi: 10.1001/archpsyc.1997.01830170091012

Green, M. F., Nuechterlein, K. H., Breitmeyer, B., and Mintz, J. (1999). Backward masking in unmedicated schizophrenic patients in psychotic remission possible reflection of aberrant cortical oscillation. Am. J. Psychiatry 156, 1367-1373.

Green, M. F., Nuechterlein, K. H., and Mintz, J. (1994). Backward masking in schizophrenia and mania: I. specifying a mechanism. Arch. Gen. Psychiatry 51, 939-944. doi: 10.1001/archpsyc. 1994.03950120011003

Gross, J., Kujala, J., Hamalainen, M., Timmermann, L., Schnitzler, A., and Salmelin, R. (2001). Dynamic imaging of coherent sources: studying neural interactions in the human brain. Proc. Natl. Acad. Sci. U.S.A. 98, 694-699. doi 10.1073/pnas.98.2.694

Gruber, T., Trujillo-Barreto, N. J., Giabbiconi, C., Valdés-Sosa, P. A., and Müller, M. M. (2006). Brain electrical tomography (BET) analysis of induced gamma band responses during a simple object recognition task. Neuroimage 29, 888-900. doi 10.1016/j.neuroimage.2005.09.004

Grützner, C., Uhlhaas, P. J., Genc, E., Kohler, A., Singer W., and Wibral, M. (2010). Neuroelectromagnetic correlates of perceptual closure processes. J. Neurosci. 30, 8342-8352. doi 10.1523/JNEUROSCI.5434-09.2010

Grützner, C., Wibral, M., Sun, L. Rivolta, D., Singer, W., Maurer, K., et al. (2013). Deficits in high- $\quad(>60 \mathrm{~Hz})$ gamma-band oscillations during visual processing in schizophrenia. Front. Hum. Neurosci. 7:88. doi: 10.3389/fnhum.2013.00088

Hadjipapas, A., Adjamian, P., Swettenham, J. B., Holliday, I. E., and Barnes, G. R. (2007). Stimuli of varying spatial scale induce gamma activity with distinct temporal characteristics in human visual cortex. Neuroimage 35, 518-530. doi: $\quad 10.1016 /$ j.neuroimage.2007. 01.002

Haenschel, C., Bittner, R. A., Waltz, J. Haertling, F., Wibral, M., Singer W., et al. (2009). Cortical oscillatory activity is critical for working memory as revealed by deficits in early-onset schizophrenia. $J$. Neurosci. 29, 9481-9489. doi 10.1523/JNEUROSCI.1428-09.2009

Haenschel, C., Linden, D. E., Bittner, R. A., Singer, W., and Hanslmayr, S. (2010). Alpha phase locking predicts residual working memory performance in schizophrenia. Biol. Psychiatry 68, 595-598. doi: 10.1016/j.biopsych.2010.06.013

Hall, M., Taylor, G., Sham, P., Schulze, K., Rijsdijk, F., Picchioni, M., et al. (2011). The early auditory gamma-band response is heritable and a putative endophenotype of schizophrenia. Schizophr. Bull. 37, 778-787. doi: 10.1093/schbul/sbp134

Hamm, J. P., Gilmore, C. S., and Clementz, B. A. (2012). Augmented gamma band auditory steady-state responses: support for NMDA hypofunction in schizophrenia. Schizophr. Res. 138, 1-7. doi: 10.1016/j.schres.2012.04.003

Hamm, J. P., Gilmore, C. S., Picchetti, N. A. M., Sponheim, S. R. and Clementz, B. A. (2011). Abnormalities of neuronal oscillations and temporal integration to low- and high-frequency auditory stimulation in schizophrenia. Biol. Psychiatry 69, 989-996. doi: 10.1016/j.biopsych.2010.11.021

Harrison, P. J., and Weinberger, D. R. (2004). Schizophrenia genes, gene expression, and neuropathology: on the matter of their convergence. Mol. Psychiatry 10, 40-68. doi: 10.1038/sj.mp.4001558

Hashimoto, T., Volk, D. W., Eggan, S. M., Mirnics, K., Pierri, J. N., Sun, Z., et al. (2003). Gene expression deficits in a subclass of GABA neurons in the prefrontal cortex of subjects with schizophrenia. J. Neurosci. 23, 6315-6326.

Hashimoto, T. M. D., Bazmi, H. H. M. S., Mirnics, K. M. D., Wu, Q. P. D., Sampson, A. R. P. D., and Lewis, D. A. M. D. (2008). Conserved regional patterns of GABA-related transcript expression in the neocortex of subjects with schizophrenia. Am. J. Psychiatry 165, 479-489. doi: 10.1176/appi.ajp.2007.07081223

Havenith, M. N., Yu, S., Biederlack, J., Chen, N., Singer, W., and Nikolić, D. (2011). Synchrony makes neurons fire in sequence, and stimulus properties determine who is ahead. J. Neurosci. 31, 8570-8584. doi 10.1523/JNEUROSCI.2817-10.2011

Herrmann, C. S. (2001). Human EEG responses to $1-100 \mathrm{~Hz}$ flicker: resonance phenomena in visual cortex and their potential correlation to cognitive phenomena. Exp. Brain Res. 137, 346-353. doi: $10.1007 / \mathrm{s} 002210100682$

Herrmann, C. S., Mecklinger, A., and Pfeifer, E. (1999). Gamma responses and ERPs in a visual classification task. Clin. Neurophysiol. 110, 636-642. doi: 10.1016/S1388-2457(99)00002-4

Herrmann, C. S., Munk, M. H. J., and Engel, A. K. (2004a). Cognitive functions of gammaband activity: memory match and utilization. Trends Cogn. Sci. (Regul. Ed.) 8, 347-355. doi: 10.1016/j.tics.2004.06.006

Herrmann, M. J., Ellgring, H., and Fallgatter, A. J. (2004b). Earlystage face processing dysfunction in patients with schizophrenia. Am. J. Psychiatry 161, 915-917. doi: 10.1176/appi.ajp.161.5.915

Hillyard, S. A., Vogel, E. K., and Luck, S. J. (1998). Sensory gain control (amplification) as a mechanism of selective attention: electrophysiological and neuroimaging evidence. Philos. Trans. R. Soc. Lond. B Biol. Sci. 
353, 1257-1270. doi: 10.1098/rstb. 1998.0281

Hipp, J. F., Engel, A. K., and Siegel, M. (2011). Oscillatory synchronization in large-scale cortical networks predicts perception. Neuron 69, 387-396. doi: 10.1016/j.neuron.2010.12.027

Hipp, J. F., and Siegel, M. (2013). Dissociating neuronal gammaband activity from cranial and ocular muscle activity in EEG. Front. Hum. Neurosci. 7:338. doi: 10.3389/fnhum.2013.00338

Hong, L. E., Summerfelt, A., Mitchell, B. D., McMahon, R. P., Wonodi, I. B., Robert, W., and Thaker, G. K. (2008). Sensory gating endophenotype based on its neural oscillatory pattern and heritability estimate. Arch. Gen. Psychiatry 65, 1008-1016. doi: 10.1001/archpsyc.65.9.1008

Hong, L. E., Summerfelt, A., Buchanan, R. W., O'Donnell, P., Thaker, G. K., Weiler, M. A., et al. (2010). Gamma and delta neural oscillations and association with clinical symptoms under subanesthetic ketamine. Neuropsychopharmacology 35, 632-640. doi: $10.1038 / n p p .2009 .168$

Hunt, M. J., Falinska, M., Łęski, S., Wójcik, D. K., and Kasicki, S. (2011). Differential effects produced by ketamine on oscillatory activity recorded in the rat hippocampus, dorsal striatum and nucleus accumbens. J. Psychopharmacol. 25, 808-821. doi: 10.1177/0269881110362126

Hutton, S. B., Murphy, F. C., Joyce, E. M., Rogers, R. D., Cuthbert, I., Barnes, T. R. E., et al. (2002). Decision making deficits in patients with first-episode and chronic schizophrenia. Schizophr. Res. 55, 249-257. doi: 10.1016/S09209964(01)00216-X

Ito, J., Maldonado, P., Singer, W., and Grün, S. (2011). Saccade-related modulations of neuronal excitability support synchrony of visually elicited spikes. Cereb. Cortex 21, 2482-2497. doi: 10.1093/cercor/bhr020

Javitt, D. C. (2009). When doors of perception close: bottom-up models of disrupted cognition in schizophrenia. Annu. Rev. Clin. Psychol. 5, 249-275. doi: 10.1146/ annurev.clinpsy.032408.153502

Jia, X., Smith, M. A., and Kohn, A. (2011). Stimulus selectivity and spatial coherence of gamma components of the local field potential. J. Neurosci. 31, 9390-9403. doi: 10.1523/JNEUROSCI.064511.2011
Jia, X., Tanabe, S., and Kohn, A. (2013a). Gamma and the coordination of spiking activity in early visual cortex. Neuron 77, 762-774. doi: 10.1016/j.neuron.2012.12.036

Jia, X., Xing, D., and Kohn, A. (2013b). No consistent relationship between gamma power and peak frequency in macaque primary visual cortex. J. Neurosci. 33, 17-25. doi: 10.1523/JNEUROSCI.1687-12.2013

Johnson, S. C., Lowery, N., Kohler, C., and Turetsky, B. I. (2005). Global-Local visual processing in schizophrenia: evidence for an early visual processing deficit. Biol. Psychiatry 58, 937-946. doi: 10.1016/j.biopsych.2005.04.053

Kahlbrock, N., Butz, M., May, E. S., and Schnitzler, A. (2012). Sustained gamma band synchronization in early visual areas reflects the level of selective attention. Neuroimage 59, 673-681. doi: 10.1016/j.neuroimage.2011.07.017

Kawaguchi, Y., and Kubota, Y. (1997). GABAergic cell subtypes and their synaptic connections in rat frontal cortex. Cereb. Cortex 7, 476-486. doi: 10.1093/cercor/7.6.476

Kegeles, L. S., Mao, X. S., Arielle, D., Girgis, R. Ojeil, N., Xu, X., et al. (2012). Elevated prefrontal cortex [gamma]-aminobutyric acid and glutamate-glutamine levels in schizophrenia measured in vivo with proton magnetic resonance spectroscopy. Arch. Gen. Psychiatry 69, 449-459. doi: 10.1001/archgenpsychiatry.2011.1519

Keil, A., Müller, M. M., Ray, W. J., Gruber, T., and Elbert, T. (1999). Human gamma band activity and perception of a gestalt. J. Neurosci. 19, 7152-7161.

Kéri, S., Kelemen, O., Benedek, G., and Janka, Z. (2001). Different trait markers for schizophrenia and bipolar disorder: a neurocognitive approach. Psychol. Med. 31, 915-922. doi: 10.1017/S0033291701004068

Kim, D., Wylie, G., Pasternak, R., Butler, P. D., and Javitt, D. C. (2006). Magnocellular contributions to impaired motion processing in schizophrenia. Schizophr. Res. 82, 1-8. doi: 10.1016/j.schres.2005.10.008

Kirov, G., Pocklington, A. J., Holmans, P., Ivanov, D., Ikeda, M., Ruderfer, D., et al. (2012). De novo CNV analysis implicates specific abnormalities of postsynaptic signalling complexes in the pathogenesis of schizophrenia. Mol. Psychiatry 17, 142-153. doi: 10.1038/mp.2011.154 Kittelberger, K., Hur, E., Sazegar, S., Keshavan, V., and Kocsis, B.
(2012). Comparison of the effects of acute and chronic administration of ketamine on hippocampal oscillations: relevance for the NMDA receptor hypofunction model of schizophrenia. Brain Struct. Funct. 217, 395-409. doi: 10.1007/s00429-011-0351-8

Klosterkötter, J., Hellmich, M., Steinmeyer, E. M., and SchultzeLutter, F. (2001). DIagnosing schizophrenia in the initial prodromal phase. Arch. Gen. Psychiatry 58, 158-164. doi: 10.1001/archpsyc.58.2.158

Koelewijn, L., Rich, A. N. Muthukumaraswamy, S. D., and Singh, K. D. (2013). Spatial attention increases high-frequency gamma synchronisation in human medial visual cortex. Neuroimage 79, 295-303. doi: 10.1016/j.neuroimage.2013.04.108

Kopell, N., Kramer, M. A., Malerba, P., and Whittington, M. A. (2010). Are different rhythms good for different functions? Front. Hum. Neurosci. 4:187. doi: 10.3389/fnhum.2010.00187

Kraepelin, E. (1971). Dementia Praecox and Paraphrenia. Huntington, NY: R. E. Krieger Pub. Co. (Originally published in 1919).

Kreiter, A., and Singer, W. (1996). Stimulus-dependent synchronization of neuronal responses in the visual cortex of the awake macaque monkey. J. Neurosci. 16, 2381-2396.

Krishnan, G. P., Vohs, J. L., Hetrick, W. P., Carroll, C. A., Shekhar, A., Bockbrader, M. A., et al. (2005). Steady state visual evoked potential abnormalities in schizophrenia. Clin. Neurophysiol. 116, 614-624. doi: 10.1016/j.clinph.2004.09.016

Kwon, J. S., O'Donnell, B. F., Wallenstein, G. V., Greene, R. W., Hirayasu, Y., Nestor, P. G., et al. (1999). Gamma frequency-range abnormalities to auditory stimulation in schizophrenia. Arch. Gen. Psychiatry 56, 1001-1005. doi: 10.1001/archpsyc.56.11.1001

Lachaux, J. P., Chavez, M., and Lutz, A. (2003). A simple measure of correlation across time, frequency and space between continuous brain signals. J. Neurosci. Methods 123, 175-188. doi: 10.1016/S0165-0270(02)00358-8

Lachaux, J. P., George, N., TallonBaudry, C., Martinerie, J., Hugueville, L., Minotti, L., et al. (2005). The many faces of the gamma band response to complex visual stimuli. Neuroimage 25, 491-501. doi: 10.1016/j.neuroimage.2004.11.052
Lachaux, J. P., Rodriguez, E., Martinerie, J., and Varela, F. J. (1999). Measuring phase synchrony in brain signals. Hum. Brain Mapp. 8, 194-208. doi: 10.1002/(SICI) 10 97-0193(1999)8:4<194::AID-HBM 4>3.0.CO;2-C

Lakatos, P., Schroeder, C. E., Leitman, D. I., and Javitt, D. C. (2013). Predictive suppression of cortical excitability and its deficit in schizophrenia. $J$. Neurosci. 33, 11692-11702. doi: 10.1523/JNEUROSCI.0010-13.2013

Lalor, E. C., De Sanctis, P., Krakowski, M. I., and Foxe, J. J. (2012). Visual sensory processing deficits in schizophrenia: is there anything to the magnocellular account? Schizophr. Res. 139, 246-252. doi: 10.1016/j.schres.2012.05.022

Lewis, D. A. (2000). GABAergic local circuit neurons and prefrontal cortical dysfunction in schizophrenia. Brain Res. Rev. 31, 270-276. doi: 10.1016/S0165-0173(99)00042-9

Lewis, D. A., Curley, A. A., Glausier, J. R., and Volk, D. W. (2012). Cortical parvalbumin interneurons and cognitive dysfunction in schizophrenia. Trends Neurosci. 35, 57-67. doi: 10.1016/j.tins.2011.10.004

Lewis, D. A., Fish, K. N., Arion, D., and Gonzalez-Burgos, G. (2011). Perisomatic inhibition and cortical circuit dysfunction in schizophrenia. Curr. Opin. Neurobiol. 21, 866-872. doi: 10.1016/j.conb.2011.05.013

Lewis, D. A., Hashimoto, T., and Volk, D. W. (2005). Cortical inhibitory neurons and schizophrenia. Nat. Rev. Neurosci. 6, 312-324. doi: 10.1038/nrn1648

Lima, B., Singer, W., Chen, N., and Neuenschwander, S. (2010). Synchronization dynamics in response to plaid stimuli in monkey V1. Cereb. Cortex 20, 1556-1573. doi: 10.1093/cercor/bhp218

Lima, B., Singer, W., and Neuenschwander, S. (2011) Gamma responses correlate with temporal expectation in monkey primary visual cortex. J. Neurosci. 31, 15919-15931. doi 10.1523/JNEUROSCI.0957-11.2011

Lukatch, H. S., Kiddoo, C. E., and MacIver, M. B. (2005). Anesthetic-induced burst suppression EEG activity requires glutamate-mediated excitatory synaptic transmission. Cereb. Cortex 15, 1322-1331. doi: $10.1093 /$ cercor/bhi015

Lutzenberger, W., Pulvermüller, F., Elbert, T., and Birbaumer, N. (1995). Visual stimulation alters local $40-\mathrm{Hz}$ responses 
in humans: an EEG-study. Neurosci. Lett. 183, 39-42. doi: 10.1016/0304-3940(94)11109-V

Mann, E. O., and Paulsen, O. (2007). Role of GABAergic inhibition in hippocampal network oscillations. Trends Neurosci. 30, 343-349. doi: 10.1016/j.tins.2007.05.003

Martinez, A., Anllo-Vento, L., Sereno, M. I., Frank, L. R., Buxton, R. B., Dubowitz, D. J., et al. (1999). Involvement of striate and extrastriate visual cortical areas in spatial attention. Nat. Neurosci. 2, 364-369. doi: $10.1038 / 7274$

Martinovic, J., and Busch, N. A. (2011). High frequency oscillations as a correlate of visual perception. Int. J. Psychophysiol. 79, 32-38. doi: 10.1016/j.ijpsycho.2010.07.004

Meehl, P. E. (1992). Factors and taxa, traits and types, differences of degree and differences in kind. J. Pers. 60, 117-174. doi: 10.1111/j.14676494.1992.tb00269.x

Melloni, L., Molina, C., Pena, M., Torres, D., Singer, W., and Rodriguez, E. (2007). Synchronization of neural activity across cortical areas correlates with conscious perception. J. Neurosci. 27, 2858-2865. doi: 10.1523/JNEUROSCI.4623-06.2007

Melloni, L., Schwiedrzik, C. M., Rodriguez, E., and Singer, W. (2009). (Micro)Saccades, corollary activity and cortical oscillations. Trends Cogn. Sci. (Regul. Ed.) 13, 239-245. doi: 10.1016/j.tics.2009.03.007

Merigan, W. H., and Maunsell, J. H. R. (1993). How parallel are the primate visual pathways? Annu. Rev. Neurosci. 16, 369-402. doi: 10.1146/ annurev.ne.16.030193.002101

Minzenberg, M. J., Firl, A. J., Yoon, J. H., Gomes, G. C., Reinking, C., and Carter, C. S. (2010). Gamma oscillatory power is impaired during cognitive control independent of medication status in first-episode schizophrenia. Neuropsychopharmacology 35, 2590-2599. doi: 10.1038/npp.2010.150

Mirnics, K., Middleton, F. A., Marquez, A., Lewis, D. A., and Levitt, P. (2000). Molecular characterization of schizophrenia viewed by microarray analysis of gene expression in prefrontal cortex. Neuron 28, 53-67. doi: 10.1016/S0896-6273(00)00085-4

Mooney, C. M., and Ferguson, G. A. (1951). A new closure test. Can. J. Exp. Psychol. 5, 129-133. doi: 10.1037/h0083540

Muthukumaraswamy, S. (2013). High-frequency brain activity and muscle artifacts in MEG/EEG: a review and recommendations. Front. Hum. Neurosci. 7:138. doi: 10.3389/fnhum.2013.00138

Muthukumaraswamy, S. D., and Singh, K. D. (2008). Spatiotemporal frequency tuning of BOLD and gamma band MEG responses compared in primary visual cortex. Neuroimage 40, 1552-1560. doi: 10.1016/j.neuroimage.2008.01.052

Muthukumaraswamy, S. D., and Singh, K. D. (2013). Visual gamma oscillations: the effects of stimulus type, visual field coverage and stimulus motion on MEG and EEG recordings. Neuroimage 69, 223-230. doi: 10.1016/ j.neuroimage.2012.12.038

Muthukumaraswamy, S. D., Singh, K. D., Swettenham, J. B., and Jones, D. K. (2010). Visual gamma oscillations and evoked responses: variability, repeatability and structural MRI correlates. Neuroimage 49, 3349-3357. doi: 10.1016/j.neuroimage.2009.11.045

Nikolić, D., Fries, P., and Singer, W. (2013). Gamma oscillations: precise temporal coordination without a metronome. Trends Cogn. Sci. (Regul. Ed.) 17, 54-55. doi: 10.1016/j.tics.2012.12.003

Nowak, L. G., and Bullier, J. (1997). "The timing of information transfer in the visual system," in Cerebral Cortex. Extrastriate Cortex in Primates, Vol. 12, eds K. S. Rockland, J. H. Kaas, and A. Peters (New York, NY: Plenum Press), 205-241.

Núñez, D., Rauch, J., Herwig, K., Rupp, A., Andermann, M., Weisbrod, M., et al. (2013). Evidence for a magnocellular disadvantage in early-onset schizophrenic patients: a source analysis of the N80 visual-evoked component. Schizophr. Res. 144, 16-23. doi: 10.1016/j.schres.2012.12.007

O’Donnell, B. F., Vohs, J. L., Hetrick, W. P., Carroll, C. A., and Shekhar, A. (2004). Auditory event-related potential abnormalities in bipolar disorder and schizophrenia. Int. J. Psychophysiol. 53, 45-55. doi: 10.1016/j.ijpsycho.2004.02.001

O’Tuathaigh, C. M. P., Babovic, D., O’Meara, G., Clifford, J. J., Croke, D. T., and Waddington, J. L. (2007). Susceptibility genes for schizophrenia: characterisation of mutant mouse models at the level of phenotypic behaviour. Neurosci. Biobehav. Rev. 31, 60-78. doi: 10.1016/j.neubiorev.2006.04.002

Onitsuka, T. M. D., Niznikiewicz, M. A. P. D., Spencer, K. M. P. D., Frumin, M. M. D., Kuroki, N.
M. D., Lucia, L. C. B. S., et al. (2006). Functional and structural deficits in brain regions subserving face perception in schizophrenia. Am. J. Psychiatry 163, 455-462. doi: 10.1176/appi.ajp.163.3.455

Oribe, N., Hirano, Y., Kanba, S., del Re, E. C., Seidman, L. J., MesholamGately, R., et al. (2013). Early and late stages of visual processing in individuals in prodromal state and first episode schizophrenia: an ERP study. Schizophr. Res. 146, 95-102. doi: 10.1016/j.schres.2013.01.015

Osipova, D., Hermes, D., and Jensen, O. (2008). Gamma power is phase-locked to posterior alpha activity. PLoS ONE 3:e3990. doi: 10.1371/journal.pone.0003990

Özerdem, A., Güntekin, B., Saatçi, E., Tunca, Z., and Başar, E. (2010). Disturbance in long distance gamma coherence in bipolar disorder. Prog. Neuro-Psychopharmacol. Biol. Psychiatry 34, 861-865.

Palanca, B. J., and DeAngelis, G. C. (2005). Does neuronal synchrony underlie visual feature grouping? Neuron 46, 333-346. doi: 10.1016/j.neuron.2005.03.002

Pernet, C. R., Sajda, P., and Rousselet, G. A. (2011). Single-trial analyses: why bother? Front. Psychol. 2:322. doi: 10.3389/fpsyg.2011.00322

Perry, G., Hamandi, K., Brindley, L. M., Muthukumaraswamy, S. D., and Singh, K. D. (2013). The properties of induced gamma oscillations in human visual cortex show individual variability in their dependence on stimulus size. Neuroimage 68, 83-92. doi: 10.1016/j.neuroimage.2012.11.043

Phillips, K. G., Cotel, M. C., McCarthy, A. P., Edgar, D. M., Tricklebank, M., O'Neill, M. J., et al. (2012). Differential effects of NMDA antagonists on high frequency and gamma EEG oscillations in a neurodevelopmental model of schizophrenia. Neuropharmacology 62, 1359-1370. doi: 10.1016/ j.neuropharm.2011.04.006

Place, E. J. S., and Gilmore, G. C. (1980). Perceptual organization in schizophrenia. J. Abnorm. Psychol. 89, 409-418. doi: 10.1037/0021843X.89.3.409

Plomp, G., Roinishvili, M., Chkonia, E., Kapanadze, G., Kereselidze, M., Brand, A., et al. (2013). Electrophysiological evidence for ventral stream deficits in schizophrenia patients. Schizophr. Bull. 39, 547-554. doi: $10.1093 /$ schbul/sbr175

Ray, S., and Maunsell, J. H. R. (2010). Differences in gamma frequencies across visual cortex restrict their possible use in computation. Neuron 67, 885-896. doi: 10.1016/j.neuron.2010.08.004

Ray, S., Ni, A. M., and Maunsell, J. H. R. (2013). Strength of gamma rhythm depends on normalization. PLoS Biol. 11:e1001477. doi: 10.1371/journal.pbio.1001477

Revonsuo, A., Wilenius-Emet, M., Kuusela, J., and Lehto, M. (1997). The neural generation of a unified illusion in human vision. Neuroreport 8, 3867-3870. doi: $\quad 10.1097 / 00001756-1997122$ 20-00006

Roach, B. J., and Mathalon, D. H. (2008). Event-related EEG time-frequency analysis: an overview of measures and an analysis of early gamma band phase locking in schizophrenia. Schizophr. Bull. 34, 907-926. doi: 10.1093/schbul/sbn093

Roberts, M., Lowet, E., Brunet, N., Ter Wal, M., Tiesinga, P., Fries, P., et al. (2013). Robust gamma coherence between macaque V1 and V2 by dynamic frequency matching. Neuron 78, 523-536. doi: 10.1016/j.neuron.2013.03.003

Rodriguez, E., George, N., Lachaux, J. P., Martinerie, J., Renault, B., and Varela, F. J. (1999). Perception's shadow: long-distance synchronization of human brain activity. Nature 397, 430-433. doi: 10.1038/ 17120

Romei, V., Driver, J., Schyns, P. G., and Thut, G. (2011). Rhythmic TMS over parietal cortex links distinct brain frequencies to global versus local visual processing. Curr. Biol. 21, 334-337. doi: 10.1016/j.cub.2011.01.035

Roopun, A. K., Cunningham, M. O., Racca, C., Alter, K., Traub, R. D., and Whittington, M. A. (2008). Regionspecific changes in gamma and beta2 rhythms in NMDA receptor dysfunction models of schizophrenia. Schizophr. Bull. 34, 962-973. doi: 10.1093/schbul/sbn059

Ross, C. A., Margolis, R. L., Reading, S. A. J., Pletnikov, M., and Coyle, J. T. (2006). Neurobiology of schizophrenia. Neuron 52, 139-153. doi: 10.1016/j.neuron. 2006.09.015

Salinas, E., and Thier, P. (2000). Gain modulation: a major computational principle of the central nervous system. Neuron 27, 15-21. doi: 10.1016/S0896-6273(00)00004-0

Sannita, W. G., Lopez, L., Piras, C., and Di Bon, G. (1995). Scalprecorded oscillatory potentials evoked by transient patternreversal visual stimulation in man. Electroencephalogr. Clin. 
Neurophysiol. 96, 206-218. doi: 10.1016/0168-5597(94)00285-M

Sauvé, K. (1999). Gamma-band synchronous oscillations: recent evidence regarding their functional significance. Conscious. Cogn. 8, 213-224. doi: 10.1006/ccog.1999.0383

Schadow, J., Lenz, D., Thaerig, S., Busch, N. A., Fründ, I., Rieger, J. W., et al. (2007). Stimulus intensity affects early sensory processing: visual contrast modulates evoked gamma-band activity in human EEG. Int. J. Psychophysiol. 66, 28-36. doi: 10.1016/j.ijpsycho.2007.05.010

Schechter, I., Butler, P. D., Silipo, G., Zemon, V., and Javitt, D. C. (2003). Magnocellular and parvocellular contributions to backward masking dysfunction in schizophrenia. Schizophr. Res. 64, 91-101. doi: 10.1016/S0920-9964(03)00008-2

Schechter, I., Butler, P. D., Zemon, V. M., Revheim, N., Saperstein, A. M., Jalbrzikowski, M., et al. (2005). Impairments in generation of earlystage transient visual evoked potentials to magno- and parvocellularselective stimuli in schizophrenia. Clin. Neurophysiol. 116, 2204-2215. doi: 10.1016/j.clinph.2005.06.013

Schroeder, C. E., and Lakatos, P. (2009). Low-frequency neuronal oscillations as instruments of sensory selection. Trends Neurosci. 32, 9-18. doi: 10.1016/j.tins.2008.09.012

Schroeder, C. E., Mehta, A. D., and Givre, S. J. (1998). A spatiotemporal profile of visual system activation revealed by current source density analysis in the awake macaque. Cereb. Cortex 8, 575-592. doi: $10.1093 /$ cercor/8.7.575

Selemon, L. D., and GoldmanRakic, P. S. (1999). The reduced neuropil hypothesis: a circuit based model of schizophrenia. Biol. Psychiatry 45, 17-25. doi: 10.1016/S0006-3223(98)00281-9

Selemon, L. D., Rajkowska, G., and Goldman-Rakic, P. S. (1995). Abnormally high neuronal density in the schizophrenic cortex: a morphometric analysis of prefrontal area 9 and occipital area 17. Arch. Gen. Psychiatry 52, 805-818. doi: 10.1001/archpsyc. 1995.03950220015005

Shadlen, M. N., and Movshon, J. A. (1999). Synchrony unbound: a critical evaluation of the temporal binding hypothesis. Neuron 24, 67-77. doi: 10.1016/S0896-6273 (00)80822-3

Siegel, M., Donner, T. H., Oostenveld, R., Fries, P., and Engel, A. K. (2008). Neuronal synchronization along the dorsal visual pathway reflects the focus of spatial attention. Neuron 60, 709-719. doi: 10.1016/j.neuron.2008.09.010

Silverstein, S. M., Knight, R. A., Schwarzkopf, S. B., West, L. L., Osborn, L. M., and Kamin, D. (1996). Stimulus configuration and context effects in perceptual organization in schizophrenia. J. Abnorm. Psychol. 105, 410-420. doi: 10.1037/0021-843X.105.3.410

Singer, W. (1999). Neuronal synchrony: a versatile code for the definition of relations? Neuron 24, 49-65, 111-25.

Singer, W., and Gray, C. M. (1995). Visual feature integration and the temporal correlation hypothesis. Annu. Rev. Neurosci. 18, 555-586. doi: 10.1146/annurev.ne.18.030195. 003011

Sohal, V. S., Zhang, F., Yizhar, O., and Deisseroth, K. (2009). Parvalbumin neurons and gamma rhythms enhance cortical circuit performance. Nature 459, 698-702. doi: 10.1038 /nature 07991

Spencer, K. M. (2009). The functional consequences of cortical circuit abnormalities on gamma oscillations in schizophrenia: insights from computational modeling. Front. Hum. Neurosci. 3:33. doi: 10.3389/neuro.09.033.2009

Spencer, K. M., Nestor, P. G., Niznikiewicz, M. A., Salisbury, D. F., Shenton, M. E., and McCarley, R. W. (2003). Abnormal neural synchrony in schizophrenia. $J$. Neurosci. 23, 7407-7411.

Spencer, K. M., Nestor, P. G., Perlmutter, R., Niznikiewicz, M. A., Klump, M. C., Frumin, M., et al. (2004). Neural synchrony indexes disordered perception and cognition in schizophrenia. Proc. Natl. Acad. Sci. U.S.A. 101, 17288-17293. doi: 10.1073/pnas.0406074101

Spencer, K. M., Niznikiewicz, M. A., Shenton, M. E., and McCarley, R. W. (2008). Sensory-evoked gamma oscillations in chronic schizophrenia. Biol. Psychiatry 63, 744-747. doi: 10.1016/j.biopsych. 2007.10.017

Staal, W. G., Pol, H. E. H., Schnack, H. G., Hoogendoorn, M. L. C., Jellema, K., and Kahn, R. S. (2000). Structural brain abnormalities in patients with schizophrenia and their healthy siblings. Am. J. Psychiatry 157, 416-421. doi: 10.1176/appi.ajp.157.3.416

Straub, R. E., Jiang, Y., MacLean, C. J., Ma, Y., Webb, B. T., Myakishev, M. V., et al. (2002). Genetic variation in the $6 \mathrm{p} 22.3$ Gene DTNBP1, the human ortholog of the mouse dysbindin gene, is associated with schizophrenia. Am. J. Hum. Genet. 71, 337-348. doi: 10.1086/341750

Streit, M., Ioannides, A., Sinnemann, T., Wolwer, W., Dammers, J., Zilles, K., et al. (2001). Disturbed facial affect recognition in patients with schizophrenia associated with hypoactivity in distributed brain regions: a magnetoencephalographic study. Am. J. Psychiatry 158, 1429-1436. doi: 10.1176/appi.ajp.158.9.1429

Streit, M., Ioannides, A. A., Liu, L., Wölwer, W., Dammers, J., Gross, J., et al. (1999). Neurophysiological correlates of the recognition of facial expressions of emotion as revealed by magnetoencephalography. Cogn. Brain Res. 7, 481-491. doi: 10.1016/S0926-6410(98)00048-2

Sullivan, P. F., Kendler, K. S., and Neale, M. C. (2003). Schizophrenia as a complex trait: evidence from a meta-analysis of twin studies. Arch. Gen. Psychiatry 60, 1187-1192. doi: 10.1001/archpsyc.60.12.1187

Sun, L., Grützner, C., Bölte, S., Wibral, M., Tozman, T., Schlitt, S., et al. (2012). Impaired gamma-band activity during perceptual organization in adults with autism spectrum disorders: evidence for dysfunctional network activity in frontal-posterior cortices. J. Neurosci. 32, 9563-9573. doi: 10.1523/JNEUROSCI.1073-12.2012

Swettenham, J. B., Muthukumaraswamy, S. D., and Singh, K. D. (2009). Spectral properties of induced and evoked gamma oscillations in human early visual cortex to moving and stationary stimuli. J. Neurophysiol. 102, 1241-1253. doi: 10.1152/jn.91044.2008

Tadin, D., Kim, J., Doop, M. L., Gibson, C., Lappin, J. S., Blake, R., et al. (2006). Weakened centersurround interactions in visual motion processing in schizophrenia. J. Neurosci. 26, 11403-11412. doi: 10.1523/JNEUROSCI.259206.2006

Tallon, C., Bertrand, O., Bouchet, P., and Pernier, J. (1995). Gamma-range activity evoked by coherent visual stimuli in humans. Eur. J. Neurosci. 7, 1285-1291. doi: 10.1111/j.14609568.1995.tb01118.x

Tallon-Baudry, C. (2009). The roles of gamma-band oscillatory synchrony in human visual cognition. Front. Biosci. 1:321-332. doi: 10.2741/3246

Tallon-Baudry, C., and Bertrand, O. (1999). Oscillatory gamma activity in humans and its role in object representation. Trends Cogn. Sci. 3, 151-162. doi: 10.1016/S13646613(99)01299-1
Tallon-Baudry, C., Bertrand, O., Delpuech, C., and Pernier, J. (1996). Stimulus specificity of phase-locked and non-phase-locked $40 \mathrm{~Hz}$ visual responses in human. J. Neurosci. 16, 4240-4249.

Tallon-Baudry, C., Bertrand, O., Delpuech, C., and Pernier, J. (1997). Oscillatory $\quad \gamma$-Band $\quad(30-70 \mathrm{~Hz})$ activity induced by a visual search task in humans. J. Neurosci. 17, 722-734.

Tallon-Baudry, C., Bertrand, O., Hénaff, M., Isnard, J., and Fischer, C. (2005). Attention modulates gamma-band oscillations differently in the human lateral occipital cortex and fusiform gyrus. Cereb. Cortex 15, 654-662. doi: 10.1093/cercor/bhh167

Thiele, A., and Stoner, G. (2003). Neuronal synchrony does not correlate with motion coherence in cortical area MT. Nature 421, 366-370. doi: $10.1038 /$ nature 01285

Thut, G., Schyns, P. G., and Gross, J. (2011a). Entrainment of perceptually relevant brain oscillations by non-invasive rhythmic stimulation of the human brain. Front. Psychol. 2:170. doi: 10.3389/fpsyg.2011.00170

Thut, G., Veniero, D., Romei, V., Miniussi, C., Schyns, P., and Gross, J. (2011b). Rhythmic TMS Causes local entrainment of natural oscillatory signatures. Curr. Biol. 21, 1176-1185. doi: 10.1016/j.cub.2011.05.049

Tiesinga, P. H., Fellous, J., Salinas, E., José, J. V., and Sejnowski, T. J. (2004a). Inhibitory synchrony as a mechanism for attentional gain modulation. J. Physiol. Paris 98, 296-314.

Tiesinga, P. H. E., Fellous, J., Salinas, E., José, J. V., and Sejnowski, T. J. (2004b). Synchronization as a mechanism for attentional gain modulation. Neurocomputing 58-60, 641-646.

Tobimatsu, S., and Celesia, G. G. (2006). Studies of human visual pathophysiology with visual evoked potentials. Clin. Neurophysiol. 117, 1414-1433. doi: 10.1016/j.clinph.2006.01.004

Traub, R. D., Bibbig, A., LeBeau, F. E. N., Buhl, E. H., and Whittington, M. A. (2004). Cellular mechanisms of neural population oscillations in the hippocampus in vitro. Annu. Rev. Neurosci. 27, 247-278. doi: 10.1146/ annurev.neuro.27.070203.144303

Turetsky, B. I., Kohler, C. G., Indersmitten, T., Bhati, M. T., Charbonnier, D., and Gur, R. C. (2007). Facial emotion recognition in schizophrenia:When 
and why does it go awry? Schizophr. Res. 94, 253-263. doi: 10.1016/j.schres.2007.05.001

Tzelepi, A., Bezerianos, T., and BodisWollner, I. (2000). Functional properties of sub-bands of oscillatory brain waves to pattern visual stimulation in man. Clin. Neurophysiol. 111, 259-269. doi: 10.1016/S13882457(99)00248-5

Uhlhaas, P., and Singer, W. (2012). Neuronal dynamics and neuropsychiatric disorders: toward a translational paradigm for dysfunctional large-scale networks. Neuron 75, 963-980. doi: 10.1016/j.neuron.2012.09.004

Uhlhaas, P. J., Linden, D. E. J., Singer, W., Haenschel, C., Lindner, M., Maurer, K., et al. (2006a). Dysfunctional long-range coordination of neural activity during gestalt perception in schizophrenia. J. Neurosci. 26, 8168-8175. doi: 10.1523/JNEUROSCI.2002-06.2006

Uhlhaas, P. J., Phillips, W. A., Mitchell, G., and Silverstein, S. M. (2006b). Perceptual grouping in disorganized schizophrenia. Psychiatry Res. 145, 105-117. doi: 10.1016/j.psychres.2005.10.016

Uhlhaas, P. J., and Mishara, A. L. (2007). Perceptual anomalies in schizophrenia: integrating phenomenology and cognitive neuroscience. Schizophr. Bull. 33, 142-156. doi: 10.1093/schbul/sbl047

Uhlhaas, P. J., Pipa, G., Lima, B., Melloni, L., Neuenschwander, S., Nikolic, D., et al. (2009). Neural synchrony in cortical networks: history, concept and current status. Front. Integr. Neurosci. 3:17. doi: 10.3389/neuro.07.017.2009

Uhlhaas, P. J., and Silverstein, S. M. (2005). Perceptual organization in schizophrenia spectrum disorders: empirical research and theoretical implications. Psychol. Bull. 131, 618-632. doi: 10.1037/0033-2909.131.4.618

Uhlhaas, P. J., and Singer, W. (2006). Neural synchrony in brain disorders: relevance for cognitive dysfunctions and pathophysiology. Neuron 52, 155-168. doi: 10.1016/j.neuron.2006.09.020

Valera, F. J., Toro, A., Roy John, E., and Schwartz, E. L. (1981). Perceptual framing and cortical alpha rhythm. Neuropsychologia 19, 675-686. doi: 10.1016/0028-3932(81)90005-1
Van Essen, D. C., and Gallant, J. L. (1994). Neural mechanisms of form and motion processing in the primate visual system. Neuron 13, 1-10. doi: 10.1016/0896-6273(94)90455-3

van Pelt, S., Boomsma, D. I., and Fries, P. (2012). Magnetoencephalography in twins reveals a strong genetic determination of the peak frequency of visually induced gamma-band synchronization. J. Neurosci. 32, 3388-3392. doi: 10.1523/JNEUROSCI.5592-11.2012

Varela, F. J., Lachaux, J. P., Rodriguez, E., and Martinerie, J. (2001). The brainweb: phase synchronization and large-scale integration. Nat. Rev. Neurosci. 2, 229-239. doi: $10.1038 / 35067550$

Vidal, J. R., Chaumon, M., O’Regan, J. K., and Tallon-Baudry, C. (2006). Visual grouping and the focusing of attention induce gammaband oscillations at different frequencies in human magnetoencephalogram signals. J. Cogn. Neurosci. 18, 1850-1862. doi: 10.1162/jocn.2006.18.11.1850

Volk, D., Austin, M., Pierri, J., Sampson, A., and Lewis, D. (2001). GABa transporter-1 mRNA in the prefrontal cortex in schizophrenia: decreased expression in a subset of neurons. Am. J. Psychiatry 158, 256-265. doi: 10.1176/appi.ajp.158.2.256

Volman, V., Behrens, M. M., and Sejnowski, T. J. (2011). Downregulation of parvalbumin at cortical GABA synapses reduces network gamma oscillatory activity. J. Neurosci. 31, 18137-18148. doi: 10.1523/JNEUROSCI.3041-11.2011

Wang, X., and Buzsáki, G. (1996). Gamma oscillation by synaptic inhibition in a hippocampal interneuronal network model. J. Neurosci. 16, 6402-6413.

White, T., Magnotta, V. A., Bockholt, H. J., Williams, S., Wallace, S., Ehrlich, S., et al. (2011). Global white matter abnormalities in schizophrenia: a multisite diffusion tensor imaging study. Schizophr. Bull. 37, 222-232. doi: 10.1093/schbul/sbp088

Whitford, T. J., Kubicki, M., Ghorashi, S., Schneiderman, J. S., Hawley, K. J., McCarley, R. W., et al. (2011a). Predicting inter-hemispheric transfer time from the diffusion properties of the corpus callosum in healthy individuals and schizophrenia patients: a combined ERP and DTI study. Neuroimage 54, 2318-2329. doi: 10.1016/j.neuroimage.2010.10.048

Whitford, T. J., Kubicki, M., and Shenton, M. E. (2011b). Diffusion tensor imaging, structural connectivity, and schizophrenia. Schizophr. Res. Treat. 2011:709523. doi: 10.1155/2011/709523

Whitham, E. M., Pope, K. J., Fitzgibbon, S. P., Lewis, T., Clark, C. R., Loveless, S., et al. (2007). Scalp electrical recording during paralysis: quantitative evidence that EEG frequencies above $20 \mathrm{~Hz}$ are contaminated by EMG. Clin. Neurophysiol. 118, 1877-1888. doi: 10.1016/j.clinph.2007.04.027

Whittington, M. A., Traub, R. D., and Jefferys, J. G. R. (1995). Synchronized oscillations in interneuron networks driven by metabotropic glutamate receptor activation. Nature 373, 612-615. doi: $10.1038 / 373612 \mathrm{a} 0$

Womelsdorf, T., and Fries, P. (2007). The role of neuronal synchronization in selective attention. Curr. Opin. Neurobiol. 17, 154-160. doi: 10.1016/j.conb.2007.02.002

Wyart, V., and Tallon-Baudry, C. (2008). Neural dissociation between visual awareness and spatial attention. J. Neurosci. 28, 2667-2679. doi: 10.1523/ JNEUROSCI.4748-07.2008

Wyart, V., and Tallon-Baudry, C. (2009). How ongoing fluctuations in human visual cortex predict perceptual awareness: baseline shift versus decision bias. J. Neurosci. 29, 8715-8725. doi: 10.1523/JNEUROSCI.0962-09.2009

Wynn, J. K., Lee, J., Horan, W. P., and Green, M. F. (2008). Using event related potentials to explore stages of facial affect recognition deficits in schizophrenia. Schizophr. Bull. 34, 679-687. doi: 10.1093/schbul/sbn047

Wynn, J. K. P. D., Light, G. A. P. D., Breitmeyer, B. P. D., Nuechterlein, K. H. P. D., and Green, M. F. P. D. (2005). Event-related gamma activity in schizophrenia patients during a visual backward-masking task. Am. J. Psychiatry 162, 2330-2336. doi: 10.1176/appi.ajp.162.12.2330

Yang, E., Tadin, D., Glasser, D. M., Hong, S. W., Blake, R., and Park, S. (2013). Visual context processing in schizophrenia.
Clin. Psychol. Sci. 1, 5-15. doi: 10.1177/2167702612464618

Yeap, S. M. R. C. P., Kelly, S. P., Sehatpour, P., Magno, E., Javitt, D. C., Garavan, H., et al. (2006). Early visual sensory deficits as endophenotypes for schizophrenia: high-density electrical mapping in clinically unaffected firstdegree relatives. Arch. Gen. Psychiatry 63, 1180-1188. doi: 10.1001/archpsyc.63.11.1180

Yoon, J. H., Maddock, R. J., Rokem, A., Silver, M. A., Minzenberg, M. J., Ragland, J. D., et al. (2010). GABA concentration is reduced in visual cortex in schizophrenia and correlates with orientationspecific surround suppression. J. Neurosci. 30, 3777-3781. doi: 10.1523/JNEUROSCI.6158-09.2010 Yuval-Greenberg, S., Tomer, O., Keren, A. S., Nelken, I., and Deouell, L. Y. (2008). Transient induced gamma-band response in EEG as a manifestation of miniature saccades. Neuron 58, 429-441. doi: 10.1016/j.neuron.2008.03.027

Conflict of Interest Statement: The authors declare that the research was conducted in the absence of any commercial or financial relationships that could be construed as a potential conflict of interest.

Received: 15 May 2013; accepted: 23 August 2013; published online: 09 October 2013.

Citation: Tan H-RM, Lana L and Uhlhaas PJ (2013) High-frequency neural oscillations and visual processing deficits in schizophrenia. Front. Psychol. 4:621. doi: 10.3389/fpsyg.2013.00621

This article was submitted to Psychopathology, a section of the journal Frontiers in Psychology.

Copyright (c) 2013 Tan, Lana and Uhlhaas. This is an open-access article distributed under the terms of the Creative Commons Attribution License (CC BY). The use, distribution or reproduction in other forums is permitted, provided the original author(s) or licensor are credited and that the original publication in this journal is cited, in accordance with accepted academic practice. No use, distribution or reproduction is permitted which does not comply with these terms. 